\title{
Avaliação diagnóstica e seu uso no âmbito do projeto Educação Matemática nos Anos Iniciais - EMAI
}

\author{
Diagnostic evaluation and your use under the \\ Mathematics Education project in the Early Years - EMAI
}

\author{
Célia Maria Carolino Pires \\ celia@pucsp.br
}

\begin{abstract}
Resumo
No presente artigo nosso objetivo é apresentar algumas reflexões sobre avaliações diagnósticas relativas a números e operações, a partir da produção de alunos dos anos iniciais, por meio de protocolos coletados no início do ano letivo de 2013, no âmbito do Projeto Educação Matemática nos anos Iniciais - EMAI, da Secretaria Estadual de Educação de São Paulo. Contextualiza o projeto EMAI e situa a discussão sobre avaliação com vistas a trazer contribuições para a melhor compreensão das finalidades da avaliação diagnóstica como instrumento que além de ajudar a investigar os conhecimentos dos alunos, permite aos professores rever conceitos e valores sobre a prática, individualmente, e enquanto grupo de educadores de uma escola e de um sistema de ensino. Mostra reflexos de um trabalho centrado em expectativas de aprendizagem relacionadas aos números naturais, ao sistema de numeração decimal e ao campo aditivo e a necessidade de mais atenção aos problemas e cálculos do campo multiplicativo.
\end{abstract}

Palavras Chave: Educação Matemática. Avaliação Diagnóstica. Anos Iniciais.

\begin{abstract}
In this article our object is to present some reflections on diagnostic tests related to numbers and operations, from the production of students in the early years, through protocols collected at the beginning of school year of 2013, under the "Projeto Educação Matemática nos anos Iniciais" - EMAI, of "Secretaria Estadual de Educação de São Paulo". Contextualizes the project EMAI and situates the discussion of race in order to bring contributions to better understanding of the purposes of the test as a diagnostic instrument that besides helping to investigate students' knowledge, allows teachers to review concepts and values on the practice, individually, and as a group of educators from a school and a school system. This reflects work-centered learning expectations related to the natural numbers, the decimal system and the additive field and the need for more attention to the problems and calculations of the field multiplicative.
\end{abstract}

Keywords: Mathematics Education. Diagnostic Evaluation. Early Years.

\section{Contextualizando o Projeto EMAI}

As reflexões apresentadas neste texto têm como cenário um projeto em desenvolvimento na Secretaria Estadual de Educação de São Paulo, denominado Educação Matemática nos Anos Iniciais - EMAI, que concebemos e coordenamos junto à Coordenadoria de Gestão da Educação Básica - CGEB. Compreende um conjunto de ações que articulam o processo de desenvolvimento curricular em Matemática, a formação de professores, a avaliação de 
desempenho dos estudantes, elementos chave de promoção da qualidade da educação.

O propósito principal do Projeto, iniciado em fevereiro de 2012, é o envolvimento de todas as escolas da rede estadual que atendem alunos dos cinco anos iniciais do ensino fundamental em discussões que envolvem o processo de construção curricular, das prescrições à sua efetivação em sala de aula. A elaboração de propostas de atividades e o acompanhamento das aprendizagens dos estudantes, para reformulações que se mostrem necessárias, entendendo assim o desenvolvimento curricular como elemento dinâmico da prática educativa.

Um diferencial do Projeto é o de propor como sua ação principal, a constituição de Grupos de Educação Matemática em cada escola da rede, usando o horário destinado a aulas de trabalho pedagógico coletivo (ATPC) e atuando no formato de grupos colaborativos, organizados pelo Professor Coordenador (PC) dos Anos Iniciais do ensino Fundamental, com atividades conduzidas com a participação dos próprios professores. A estratégia de organização desses grupos colaborativos tem como finalidade estimular os professores participantes a desenvolverem habilidades comunicativas, relações profissionais interpessoais; relações simétricas e recíprocas e especialmente possibilidades de compartilhar a resolução de sua tarefa de ensinar matemática às crianças, uma responsabilidade individual, mas ao alcance do êxito do grupo. Nas reuniões, a pauta consiste do estudo e do planejamento de trajetórias hipotéticas de aprendizagem a serem realizadas em sala de aula, para posterior avaliação no grupo.

As reuniões nas escolas conduzidas pelos PC têm apoio dos Professores Coordenadores de Núcleos Pedagógicos (PCNP) das Diretorias de Ensino. Por sua vez, os Professores Coordenadores de Núcleos Pedagógicos (PCNP) participam de reuniões mensais organizadas em polos, por uma dupla de PCNP que integram o chamado Grupo de Referência de Matemática (GRM), sendo um deles um especialista em anos iniciais e o outro, um especialista em Matemática, que compartilham seus saberes sobre conteúdos matemáticos e sobre abordagens didáticas e metodológicas.

Os PCNP do GRM participam de reuniões mensais de dois dias, com a assessora do projeto e com a equipe pedagógica do Centro do Ensino Fundamental dos Anos Iniciais (CEFAI) e do Centro do Ensino Fundamental Anos Finais (CEFAF). Nas reuniões do GRM são discutidas as ações do projeto, planejadas as reuniões dos polos e das escolas e também são elaboradas e discutidas as Trajetórias Hipotéticas de Aprendizagem (THA) para cada ano da escolaridade. 
O propósito de trabalhar com a ideia de THA inspira-se nas investigações conduzidas por Simon (1995), que defende a ideia de que a consideração do objetivo da aprendizagem, as atividades de aprendizagem e pensamento e conhecimento dos estudantes são elementos importantes na construção de uma trajetória hipotética de aprendizagem - parte chave do que ele denomina Ciclo de Ensino de Matemática (Figura 1), expresso como um modelo de interrelações cíclicas dos aspectos do conhecimento do professor, pensamento, tomada de atitudes.

Figura 1: Ciclo de Ensino de Matemática abreviado (Simon, 1995)

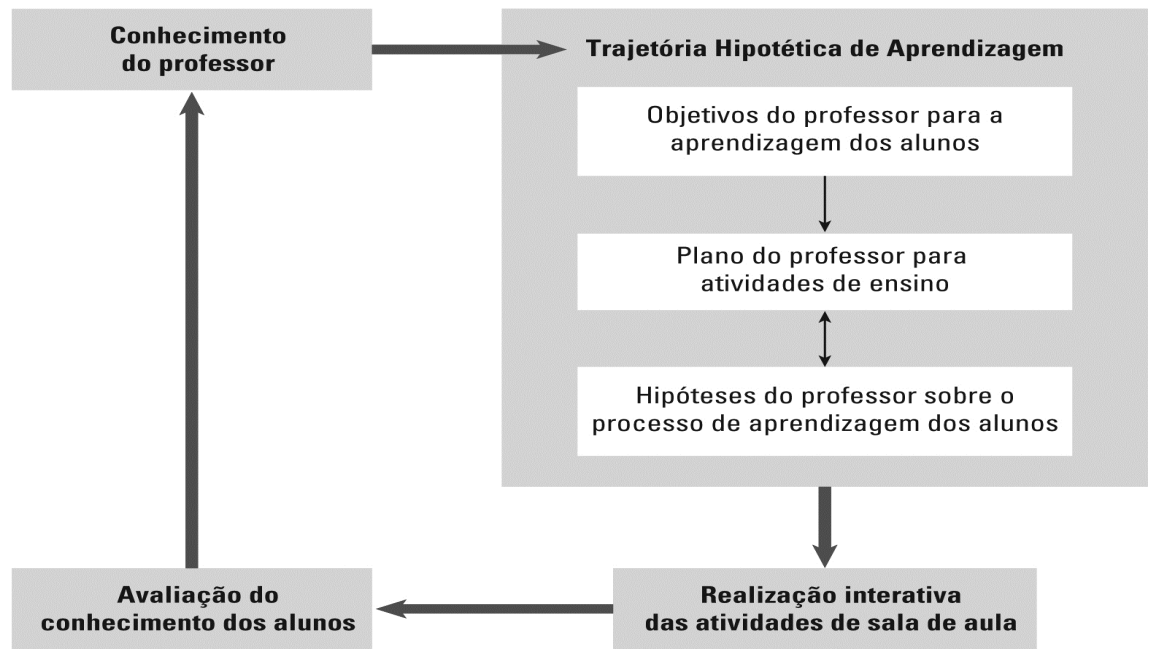

Para Simon é a meta da aprendizagem do professor para seus alunos que possibilita uma direção para uma trajetória hipotética de aprendizagem:

Usaremos o termo trajetória hipotética de aprendizagem tanto para fazer referência ao prognóstico do professor, como para o caminho que possibilitará o processamento da aprendizagem. É hipotética porque caracteriza a propensão a uma expectativa. O conhecimento individual dos estudantes ocorre de forma idiossincrática, embora freqüentemente em caminhos similares. O conhecimento do indivíduo tem alguma regularidade (cf. Steffe, Von Glaserfield, Richards e Cobb, 1983), que em sala de aula adquire com atividades matemáticas freqüentes em métodos prognósticos, e que muitos dos alunos em uma mesma sala de aula podem se beneficiar das mesmas tarefas matemáticas. (SIMON, 1995, p. 35).

Além das ideias de Simon (1995), o Projeto orienta-se por fundamentos teóricos relativos à organização curricular (Sacristán, 1998; Pires, 1995), à formação docente (Schön, 2000; Tardif, 2000; Ball, 1991; Ponte, 1998; Elbaz, 1983; Perrenoud, 1999; Garcia, 1999; Shulman, 1987; Fiorentini, 2003; Alarcão, 2003; Serrazina, 2001) e à avaliação (Hoffmann, 1991; Luchesi. 2005).

Para discussão do ensino e aprendizagem dos diversos conteúdos matemáticos envolvidos o 
projeto apoia-se nas investigações mais recentes na área de Educação Matemática, trazendo contribuições de autores como Fayol, Lerner, Sadowski, Brousseau, Vergnaud, Kieran entre outros.

O uso das THA em salas de aula pelos professores é avaliado e em cada escola são produzidos relatórios que são consolidados pelos PCNP e chegam às reuniões do GRM. Com base nas análises a partir das sínteses feitas pela rede e consolidadas em relatórios são feitas alterações, complementações e ajustes no material.

Dados coletados em junho de 2012 mostraram adesão bastante significativa ao projeto que nesse período abrangia $82 \%$ dos alunos da rede, nos cinco anos iniciais do Ensino Fundamental.

Além da formação realizada nas escolas, na perspectiva de grupos colaborativos, o Projeto EMAI oferece um Curso na modalidade EaD, composto de oito módulos, sobre os diversos blocos de conteúdo trabalhados nos anos iniciais. O público alvo são PCNP envolvidos com o EMAI pedagogos e especialistas em Matemática e Coordenadores Pedagógicos dos Anos Iniciais. Propõe-se ampliar a oferta desse curso, atendendo também aos professores.

Neste artigo, nosso propósito é trazer algumas reflexões sobre a avaliação diagnóstica, especialmente a que foi proposta no mês de fevereiro de 2013, no início do ano letivo, a partir de instrumentos oferecidos pela coordenação do projeto EMAI.

\section{As discussões sobre avaliação}

Nas reuniões do GRM é apontado, com frequência, o fato de que a mudança de concepção e de práticas por parte dos professores dos anos iniciais sobre ensino e aprendizagem nas aulas de Matemática vem ocorrendo e que, em muitos casos, é possível observar alguns frutos das reflexões realizadas nos grupos de estudo. No entanto, as concepções e práticas relativas à avaliação ainda são bastante tradicionais. Assim, mostrou-se importante retomar no debate dos grupos, ideias simples, mas fundamentais como a de que avaliar é muito mais do que aplicar uma prova e corrigi-la, mas é um processo essencial para identificar o que faremos em sala de aula com nossos alunos, em que ancoraremos novas aprendizagens, o que é preciso retomar, de onde partiremos.

No artigo "Avaliação da aprendizagem... mais uma vez", o pesquisador em avaliação Cipriano Luckesi faz revelações preocupantes. Ele relata: 
Recentemente, tenho acompanhado crianças que saíram de uma escola que atende do maternal ao final da quarta série do Ensino Fundamental, passando para a quinta série em outra escola. Impressiona-me ver a mudança dessas crianças em suas falas e em suas crenças sobre o que, nesse espaço de ensino, denominamos de avaliação. A experiência anterior dessas crianças estava relacionada com uma ação pedagógica que investe no processo da aprendizagem, a atual experiência está comprometida com o investimento no seu produto. Isso faz a diferença. Em pequeno espaço de tempo, as crianças mudaram seu centro de atenção, seus valores, assim como sua expressão. Antes, eu ouvia as crianças dizendo - "Hoje, tivemos uma atividade legal na escola" -, agora, ouço-as dizendo: "Tirei 3.2, valendo 5"; "Tirei 2, valendo 3"; “Tirei 7. Graças a Deus, já passei nessa unidade; com isso é mais fácil chegar ao final do ano com 28 pontos, necessários para a aprovação” (LUCKESI, 2005, p. 28).

\section{No texto "Avaliação Mediadora: Uma Relação Dialógica na Construção do Conhecimento", a pesquisadora Jussara Hoffmann destaca:}

\begin{abstract}
Se concebe a aprendizagem do ponto de vista comportamentalista, o professor define como uma modificação de comportamento produzida por alguém que ensina em alguém que aprende. $\mathrm{O}$ conhecimento do aluno vem dos objetos e cabe ao professor organizar os estímulos com os quais o aluno entrará em contato para aprender. A prática pedagógica consistirá, então, na transmissão clara e explícita dos conteúdos pelo professor, apresentando exemplos preferentemente concretos (organização de estímulos). Essa situação, por si só, promoverá a aprendizagem, desde que o aluno entre em contato com tais estímulos, esteja atento às situações. Assim, se o professor oferecer explicações claras, textos explicativos consistentes e organizar o ambiente pedagógico, o aluno aprenderá, exceto se não estiver presente, ou não estiver atento às explicações, ou não memorizar os dados transmitidos pelo professor, ou não cumprir as tarefas de leitura solicitadas (HOFFMANN, 1991, p. 54).
\end{abstract}

E complementa:

\begin{abstract}
A hipótese que anuncio é que uma tal visão de conhecimento positivista vincula-se a uma prática avaliativa de observação e registro de dados. Assim como supervaloriza as informações que transmite ao aluno e exige que ele permaneça alerta a tais informações, o professor também o toma como seu objeto de conhecimento, ou seja, permanece atento aos "fatos objetivos": o aluno passa a ser um objeto de estudo do professor, que o capta apenas em seus atributos palpáveis, mensuráveis, observáveis. Sua prática avaliativa revela intenções de coleta de dados em relação ao aluno, dele registrando dados precisos e fidedignos. Dessa forma, o professor não assume absolutamente a responsabilidade em relação ao fracasso do aluno. Em primeiro lugar, porque representaria assumir sua incompetência na organização do trabalho pedagógico, uma apresentação inadequada de estímulos à aprendizagem. Em segundo lugar, porque aquilo que faz geralmente se traduz em resultados positivos. Ou seja, alguns alunos, ou a maioria, aprendem. Se a ação produz modificação de comportamentos em alguns alunos, então o problema está nos alunos e não na ação do professor (HOFFMANN, 1991, p. 54).
\end{abstract}

Para Hoffman, sem ultrapassar a visão comportamentalista de conhecimento, nenhuma outra hipótese é levantada pelo professor sobre as dificuldades que os alunos apresentam, senão a sua desatenção e desinteresse. E propõe um paradigma de avaliação que se opõe ao paradigma sentencioso, classificatório e que denomina de "avaliação mediadora". 
O que pretendo introduzir neste texto é a perspectiva da ação avaliativa como uma das mediações pela qual se encorajaria a reorganização do saber. Ação, movimento, provocação, na tentativa de reciprocidade intelectual entre os elementos da ação educativa. Professor e aluno buscando coordenar seus pontos de vista, trocando ideias, reorganizando-as (HOFFMANN, 1991. P. 67).

Tal paradigma pretende opor-se ao modelo do "transmitir-verificar-registrar" e evoluir no sentido de uma ação avaliativa reflexiva e desafiadora do educador em termos de contribuir, elucidar, favorecer a troca de ideias entre e com seus alunos, num movimento de superação do saber transmitido a uma produção de saber enriquecido, construído a partir da compreensão dos fenômenos estudados.

Nas discussões com o GRM, chegamos à conclusão de que era necessário retomar a discussão sobre avaliação, na perspectiva de que além de avaliar os conhecimentos dos alunos, nós professores também precisamos rever conceitos e valores sobre nossa prática, individualmente e como grupo de educadores de uma escola, de um sistema de ensino. Em consequência, a avaliação não pode ser entendida apenas como a aplicação de provas no final de alguns conteúdos trabalhados, como tradicionalmente o foi e ainda é. Ela precisa ser realizada em todos os momentos de interação do professor com seus alunos e tem sempre uma função diagnóstica, seja em relação a atitudes, ou a conceitos e procedimentos.

\section{Reflexões sobre o que as crianças revelam}

No início do ano letivo de 2013, no âmbito do projeto EMAI foram propostas uma série de atividades para serem realizadas com o objetivo de ajudar os professores a conhecerem seus alunos e, em particular, buscar indícios sobre seus conhecimentos matemáticos. Para cada ano da escolaridade foi proposto um projeto temático com atividades que permitissem ao professor fazer essa exploração inicial. Também foram sugeridas atividades escritas, que foram organizadas em quatro blocos, sendo que no primeiro ano a avaliação se limitou aos dois primeiros, como mostra o quadro a seguir.

Quadro 1: Distribuição dos temas avaliados por ano

\begin{tabular}{|l|c|c|c|c|c|}
\cline { 2 - 6 } \multicolumn{1}{l|}{} & $\mathbf{1}^{\mathbf{0}}$ ano & $\mathbf{2}^{\circ}$ ano & $3^{\circ}$ ano & $4^{\circ}$ ano & $5^{\circ}$ ano \\
\hline Produção de escritas numéricas & $X$ & $X$ & $X$ & $X$ & $X$ \\
\hline Resolução de problemas do campo aditivo & $X$ & $X$ & $X$ & $X$ & $X$ \\
\hline
\end{tabular}




\begin{tabular}{|l|c|c|c|c|c|}
\hline $\begin{array}{l}\text { Resolução de problemas do campo } \\
\text { multiplicativo }\end{array}$ & - & $\mathbf{X}$ & $\mathbf{X}$ & $\mathbf{X}$ & $\mathbf{X}$ \\
\hline Cálculos no campo aditivo e multiplicativo & - & $\mathbf{X}$ & $\mathbf{X}$ & $\mathbf{X}$ & $\mathbf{X}$ \\
\hline
\end{tabular}

Fonte: Quadro elaborado pela autora para este documento.

As atividades diagnósticas foram, de modo geral, bem recebidas pelos professores que as utilizaram com seus alunos. Mas, o importante é que elas desencadearam uma discussão importante nas escolas, nos polos e no próprio GRM. O que fazer com as atividades? Tabular os resultados? Para quê? Como analisá-las? Como usar os resultados?

A proposta de consenso foi então a de realizar o estudo no GRM e nos polos regionais de alguns protocolos de alunos de escolas envolvidas no Projeto, com a finalidade de contribuir para a reflexão a ser feita por professores nos grupos de estudo em suas escolas a respeito da avaliação diagnóstica de seus alunos.

Protocolos foram gentilmente cedidos por escolas estaduais para a realização de análises ${ }^{1}$. Alguns exemplos foram selecionados para apresentação neste artigo, por serem bastante representativos de produções realizadas em cada ano da escolaridade.

\section{Revelações de alunos do primeiro ano}

Muito se tem dito que as crianças chegam à escola, no primeiro ano do Ensino Fundamental, com conhecimentos sobre números e hipóteses sobre as escritas numéricas. Mas que conhecimentos são esses?

$\mathrm{Na}$ avaliação diagnóstica realizada, foi proposto um ditado de números, subdividido em quatro grupos (G1 a G4). Em G1, os números ditados estão no intervalo 1 a 9. Em G2, as "dezenas exatas" e o 100. Em G3 e G4 números de duas ordens buscando identificar hipóteses sobre valor posicional.

O primeiro protocolo mostra a produção de um aluno que escreveu convencionalmente e corretamente todos os números ditados:

\footnotetext{
1 Os nomes das escolas não serão revelados e os nomes das crianças foram substituídos por nomes fictícios.
} 


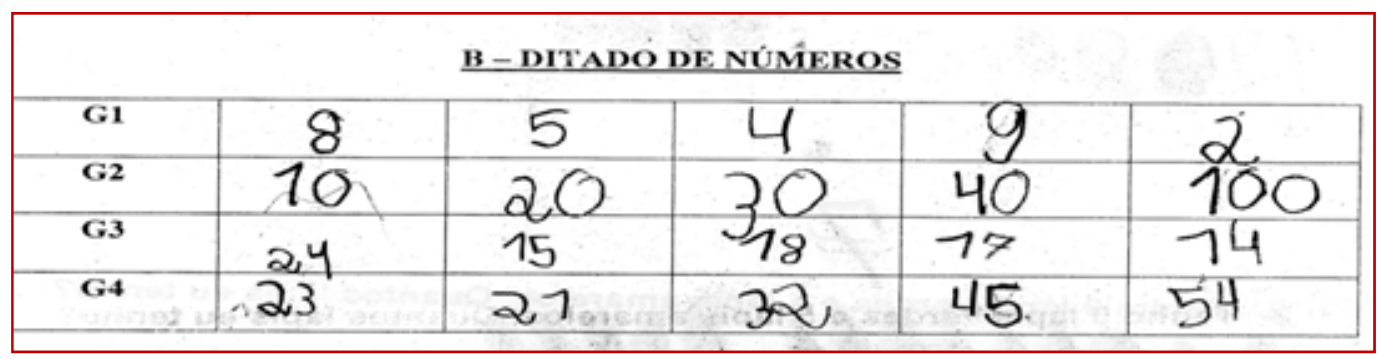

Fonte: Protocolo 1 - Caio - Primeiro Ano

O protocolo de Amália e de Beatriz, da mesma turma de Caio, mostra que as escritas do grupo G1 são realizadas corretamente por ambas, mas a partir do grupo G2, algumas escritas parecem ser aleatoriamente produzidas.

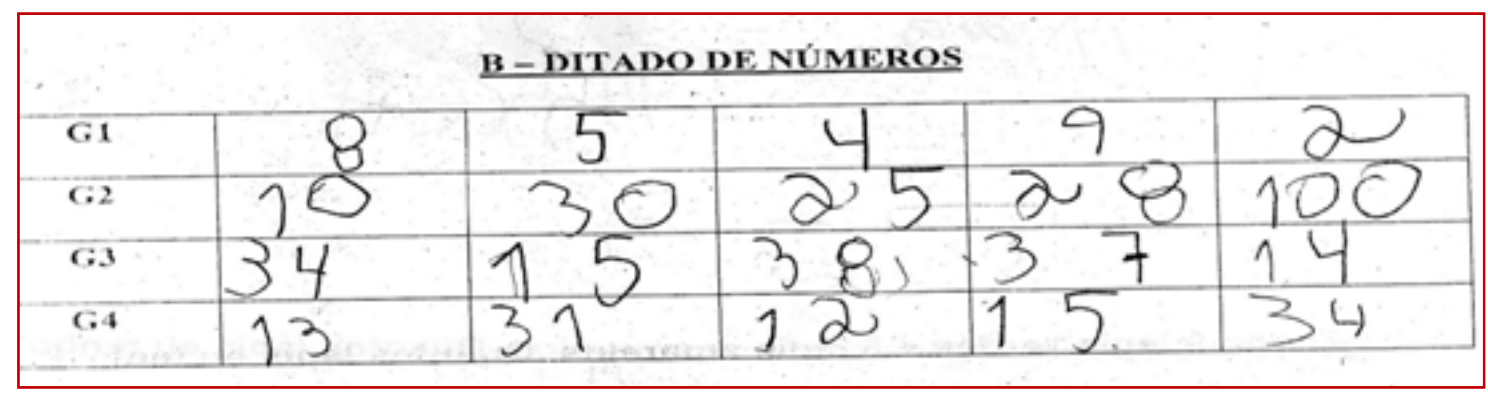

Fonte: Protocolo 2 - Amália - Primeiro Ano

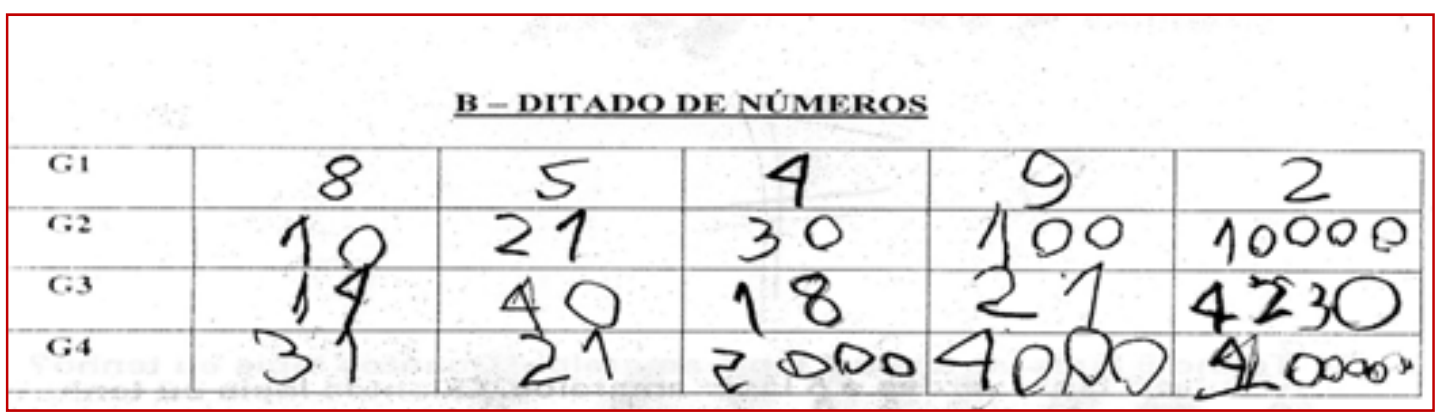

Fonte: Protocolo 3 - Beatriz - Primeiro ano

Alguns acertos podem estar relacionados ao fato de serem números familiares ou frequentes para essas meninas. Por meio de uma entrevista, é possível saber mais sobre as escritas de ambas.

Mas os conhecimentos numéricos desses alunos podem ser analisados também em função da resolução de problemas.

Caio reafirma seus conhecimentos, resolvendo os problemas de composição lidos pela professora, usando desenhos e apresentando o resultado final por meio de uma escrita numérica. 


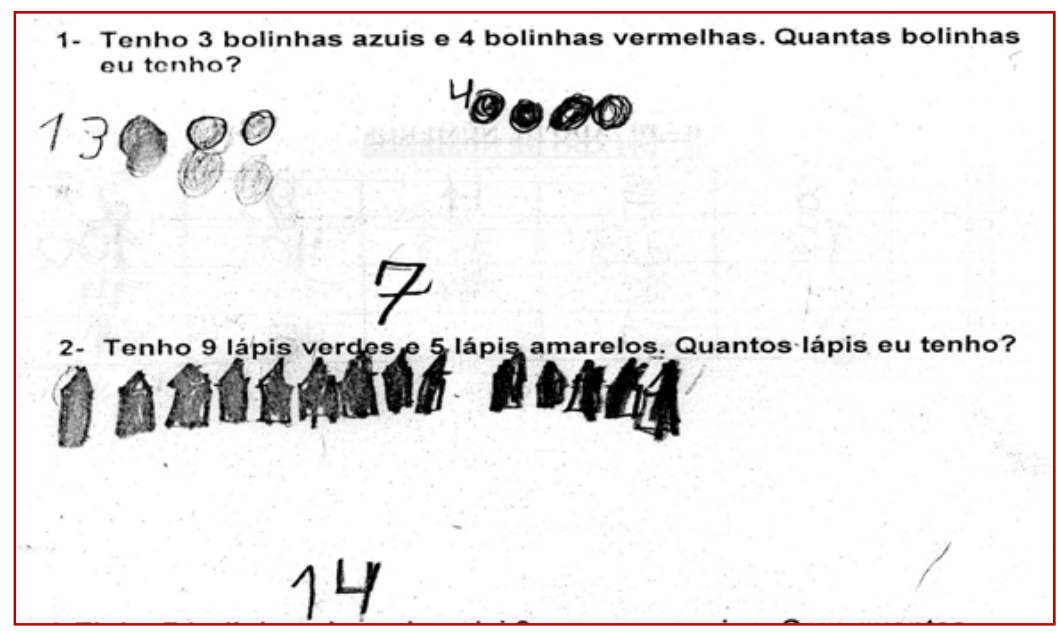

Fonte: Protocolo 4 - Caio - Primeiro Ano

Amália também resolve corretamente esses dois problemas e registra de forma clara como realizou a sobrecontagem:

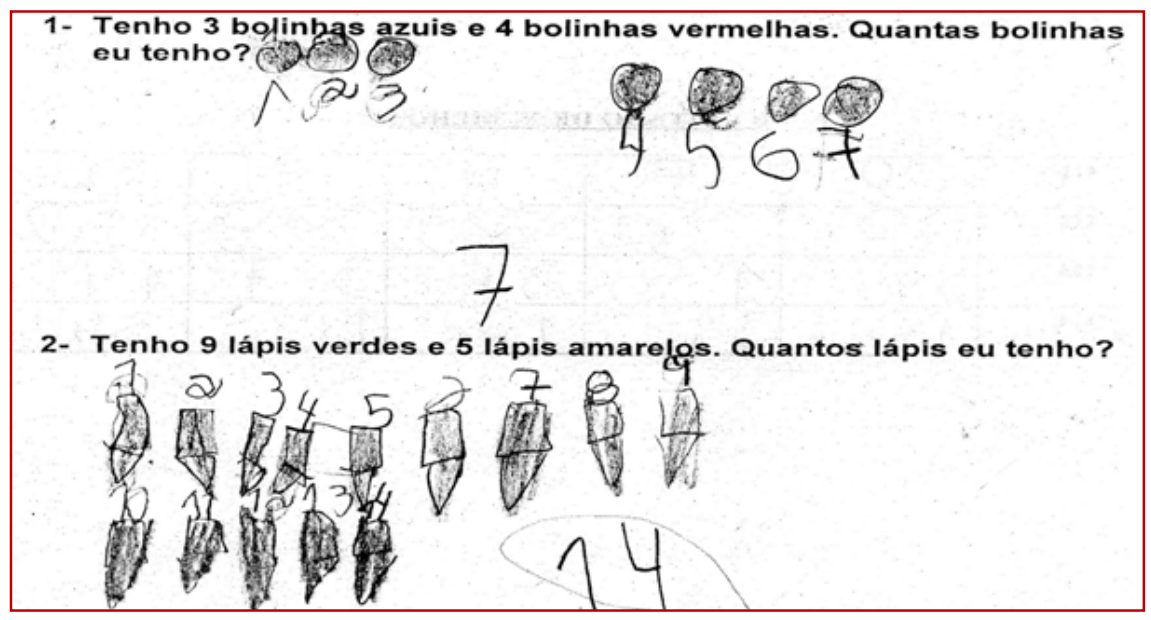

Fonte: Protocolo 5 - Amália - Primeiro Ano

Também Beatriz resolve os dois problemas desenhando corretamente as quantidades e apenas registrando 15 em lugar de 14, na totalização do segundo problema. Observe-se que a escrita espelhada do 5 no registro do resultado 15 é algo bastante comum nessa etapa da escolaridade que com a proposição de atividades numéricas vai se corrigir naturalmente. 


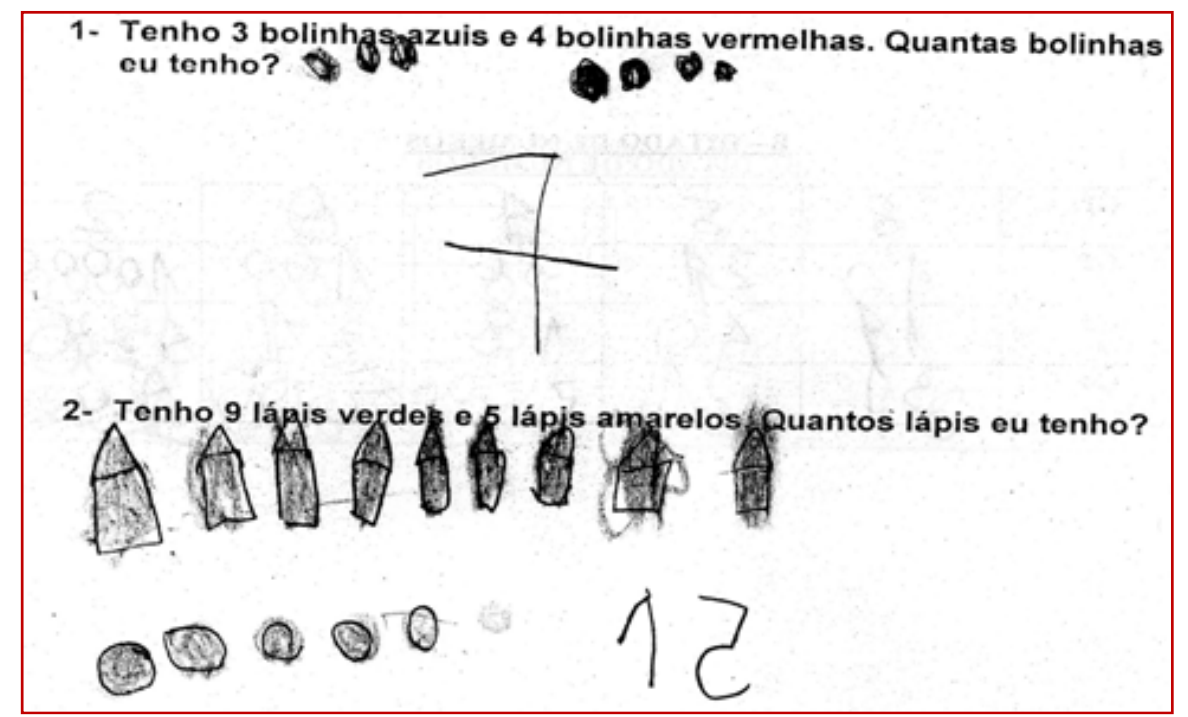

Fonte: Protocolo 6 - Beatriz - Primeiro ano

Em relação a dois problemas de transformação negativa que envolviam a ideia de subtração Caio desenha 7 bolinhas e parece apagar as 3 primeiras com a borracha concluindo que ficou com 4 bolinhas. Na outra situação desenha as 10 e apenas registra o total 6, das que restaram:

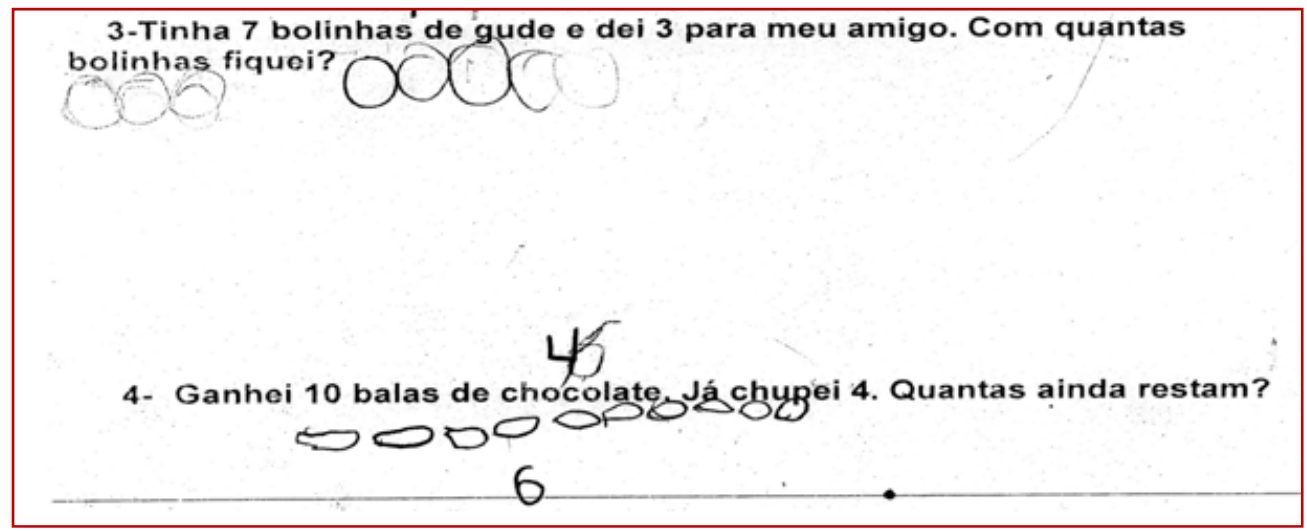

Fonte: Protocolo 7 - Caio - Primeiro Ano

Nesses problemas, Amália desenha corretamente as 7 bolinhas, mas "apaga" apenas uma, em vez de 3 e dá a resposta 6 . No segundo também responde 7 em vez de 6 . Mas parece ter ideia do que está em jogo, embora, não apresentando respostas corretas. 


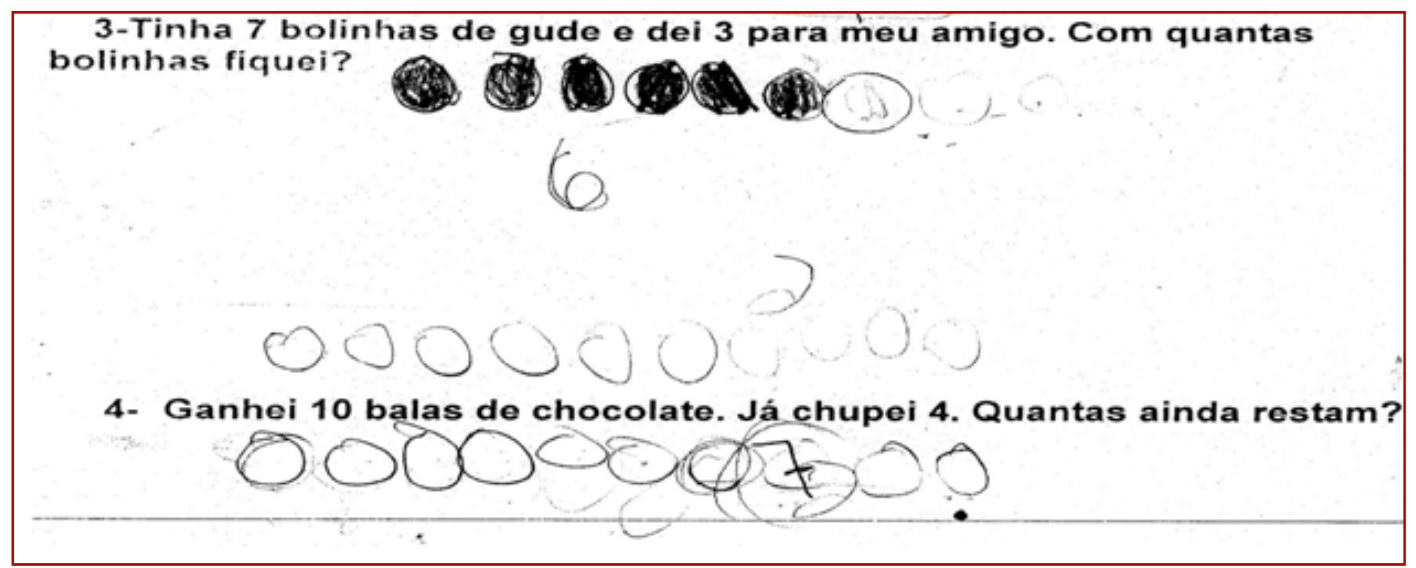

Fonte: Protocolo 8 - Amália - Primeiro ano

Beatriz também não chega a respostas corretas nas situações de subtração, mas parece também usar a estratégia de desenhar a quantidade total para depois apagar alguns desenhos e fazer a contagem do que sobrou.

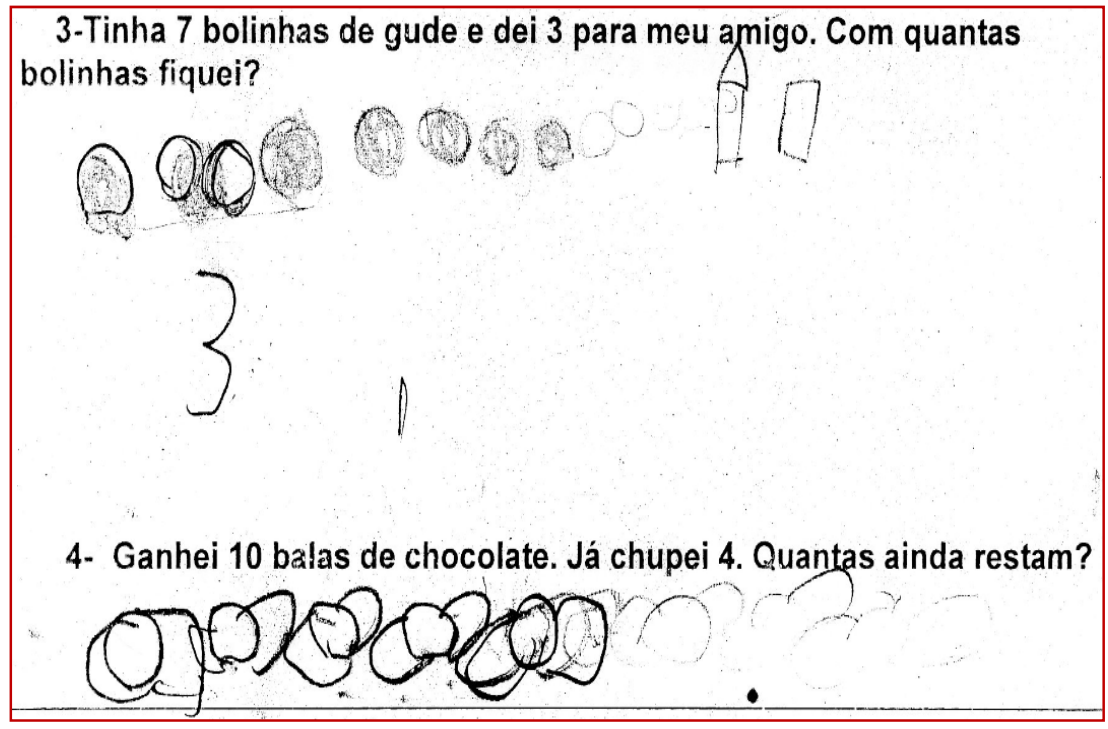

Fonte: Protocolo 9 - Beatriz - Primeiro Ano

Embora com diferenças observáveis em seus desempenhos, o fato é que a análise de algumas produções dessas crianças confirma que elas chegam à escola no primeiro ano do Ensino Fundamental, com conhecimentos sobre números e hipóteses sobre as escritas numéricas e que não se intimidam frente à resolução de problemas.

Isso mostra que um bom trabalho pode ser realizado pelos professores do primeiro ano, por meio de atividades como as apresentadas nas trajetórias hipotéticas de aprendizagem do material do EMAI. 


\section{Revelações de alunos do segundo ano}

Com relação à produção de escritas numéricas os desafios para os alunos do segundo ano foram um pouco além dos propostos para o primeiro ano.

Os números ditados podem ser vistos no protocolo abaixo, em que o aluno registra convencionalmente todos os números ditados, tanto os de dois como os de três dígitos.

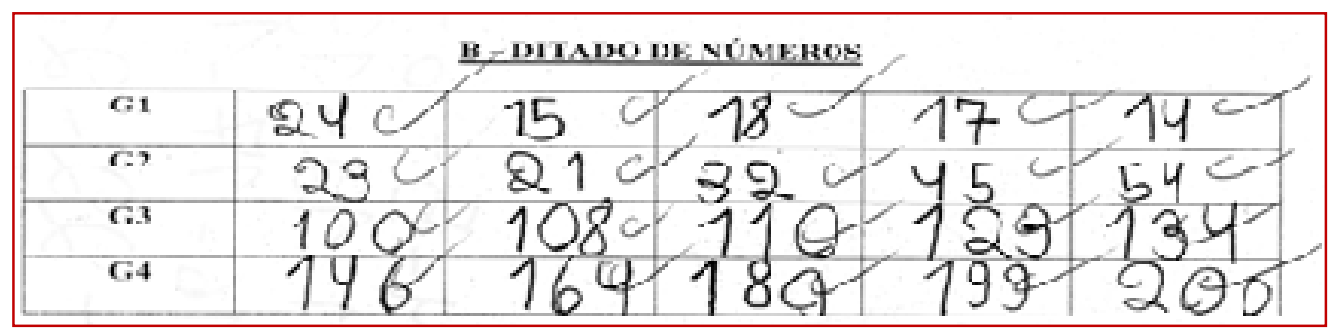

Fonte: Protocolo 10 - Luiz - Segundo ano

Em outra atividade, esse mesmo aluno realiza corretamente os cálculos de adição e comete erros na subtração, realizando adições no lugar. Mas, deixa em branco os cálculos envolvendo multiplicação e divisão. O bom desempenho nas escritas, observados no protocolo de Luiz, possibilitaria um melhor desempenho na realização de cálculos, mas é provável que essas aprendizagens não tenham sido estimuladas no ano anterior. De todo modo, o ponto de partida desse aluno para o trabalho no segundo ano é bem interessante.

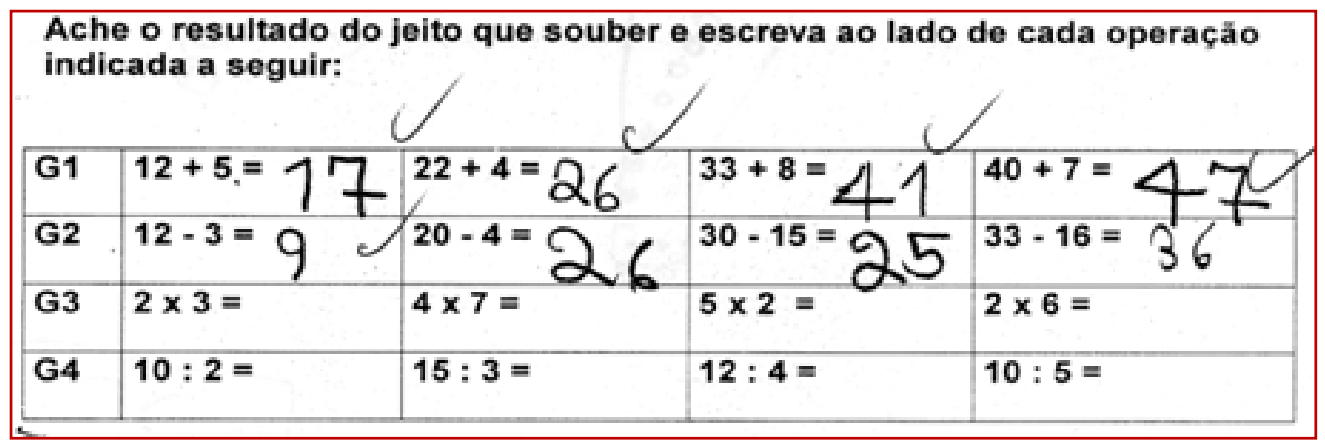

Fonte: Protocolo 11 - Luiz - Segundo ano

Na mesma turma de Luiz, Letícia e Marcos escrevem poucos números corretamente, revelando que provavelmente no primeiro ano não conseguiram ampliar seus conhecimentos sobre essas escritas, fato que deverá ser considerado por sua professora do $2^{\circ}$ ano. 


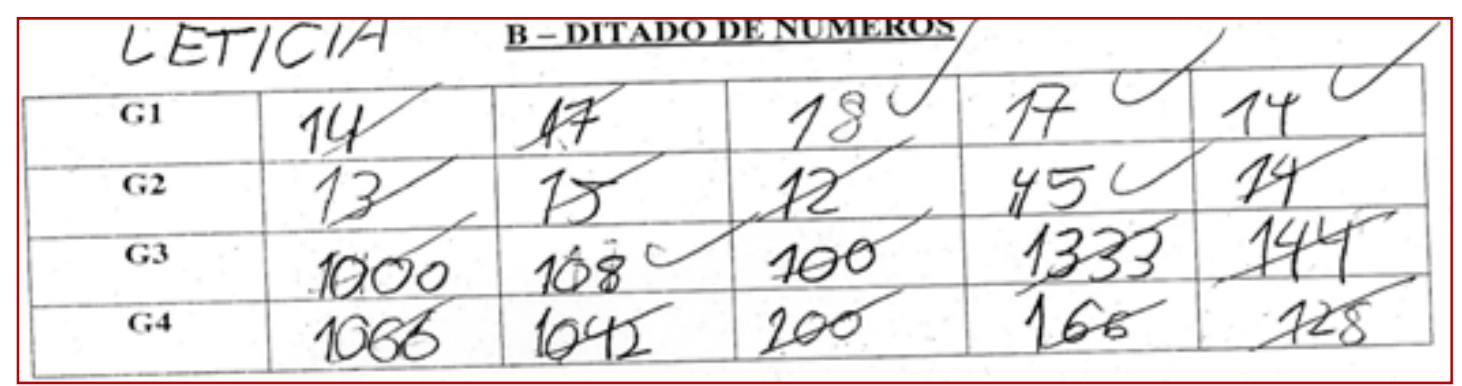

Fonte: Protocolo 12- Letícia - Segundo Ano

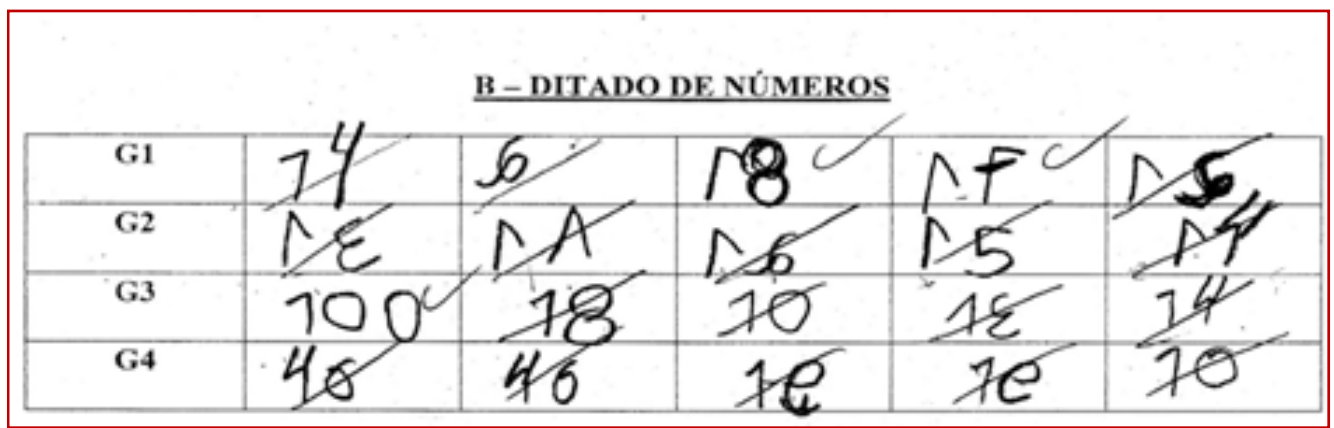

Fonte: Protocolo 13- Marcos - Segundo ano

Considerando casos como esses, as propostas de atividades apresentadas no EMAI para o segundo ano, retomam o trabalho com números e com a produção de escritas numéricas, tarefa que não pode ser descuidada pelos professores deste ano da escolaridade.

Ainda com relação a alunos do segundo ano, na avaliação diagnóstica foi proposta uma atividade de cálculo para identificar em que medida as crianças seriam capazes de identificar essas escritas (fora do contexto de resolução de um problema) e usar uma estratégia para achar o resultado.

Em relação ao calculo, Letícia apresenta uma situação similar à de Luiz:

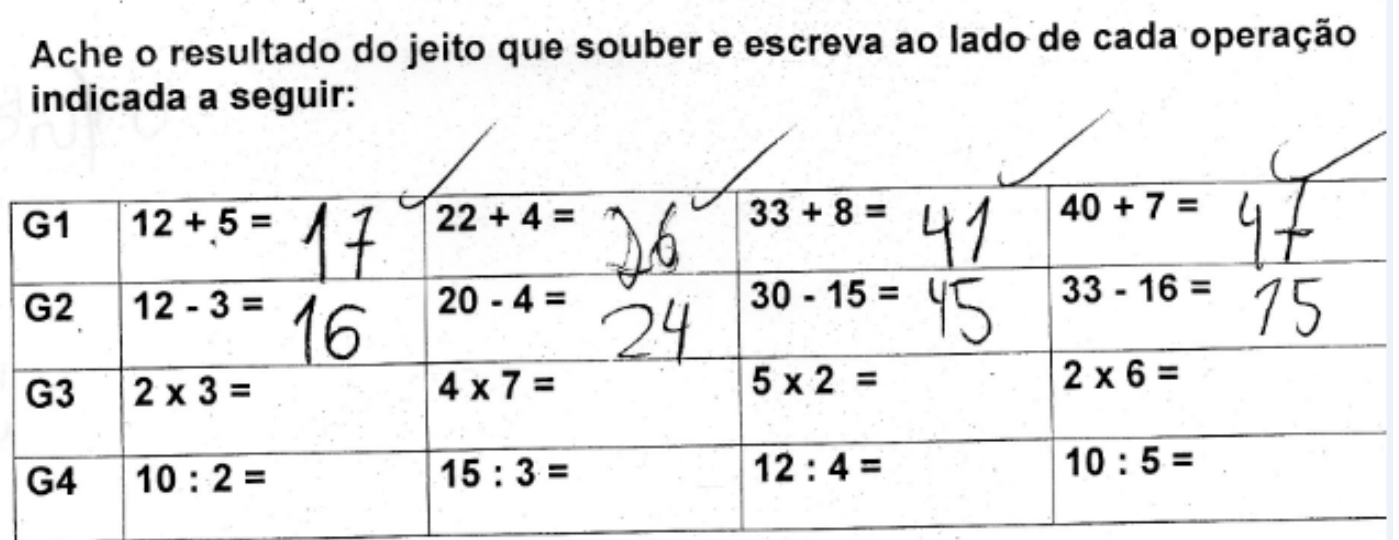

Fonte: Protocolo 14- Letícia - Segundo Ano 
Já o protocolo de Marcos mostra que o baixo desempenho no ditado de números se reflete nos cálculos em que, ao que parece, ele faz registros aleatórios para todas as operações. Seria importante examinar os protocolos de resolução de problemas desse aluno, para identificar aspectos relacionados à contagem, por exemplo. Mas, certamente, Marcos deve merecer atenção especial neste início de segundo ano.

\begin{tabular}{|c|c|c|c|c|}
\hline \multicolumn{5}{|c|}{$\begin{array}{l}\text { Ache o resultado do jeito que souber e escreva ao lado de cada operaçáo } \\
\text { indicada a seguir: }\end{array}$} \\
\hline G1 & $12+5=\measuredangle$ & $22+4=$ & $33+8=61$ & $40+7=G$ \\
\hline G2 & $12-3=$ & $20-4=$ & $30-15=k 2$ & $33-16=$ \\
\hline G3 & $2 \times 3=6$ & $4 \times 7=$ & $5 \times 2=G 3$ & $2 \times 6=67$ \\
\hline G4 & $10: 2=\sigma$ & $15: 3=7$ & $12: 4=64$ & $10: 5=G$ \\
\hline
\end{tabular}

Fonte: Protocolo 15- Marcos - Segundo Ano

\section{Revelações de alunos do terceiro ano}

Para os alunos do terceiro ano, foram propostas escritas de números com 2 e 3 dígitos e do 1000. A aluna Jerusa escreve convencionalmente todos os números ditados, exceto o 200 (quadrinho em branco).

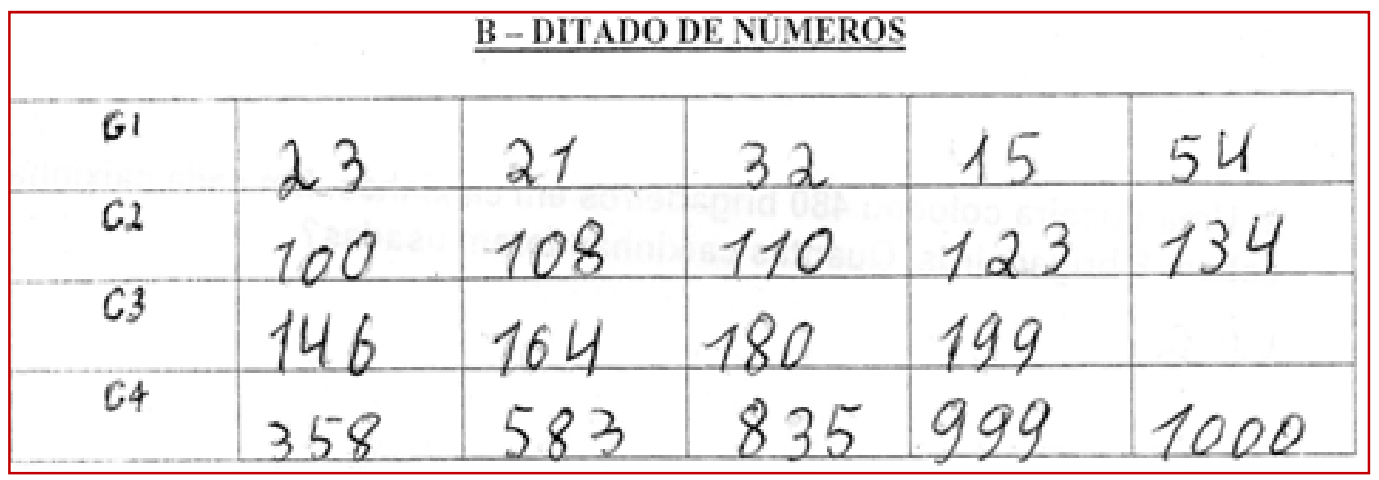

Fonte: Protocolo 16- Joana - Terceiro ano

É muito interessante analisar o protocolo dessa aluna, referente a cálculos: 


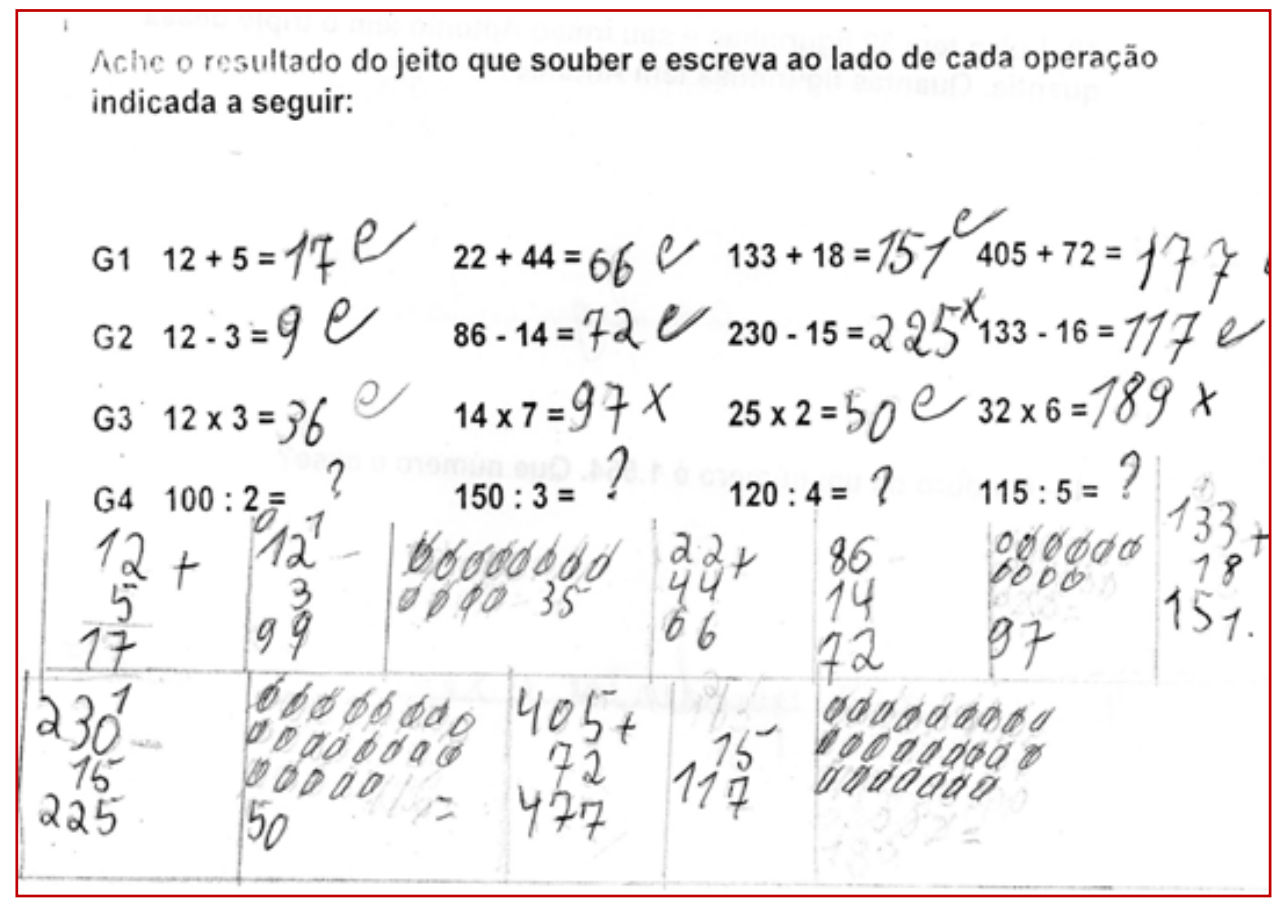

Fonte: Protocolo 17- Joana - Terceiro ano

Joana mostra bom desempenho no cálculo de adições, mas já está condicionada a montar a conta mesmo para cálculos que poderia fazer mentalmente. No seu rascunho ela faz uso de desenhos não sabemos se para apoiar o próprio cálculo ou para mostrar como fez.

O desempenho na multiplicação faz supor que alguns fatos básicos ainda não foram dominados provavelmente. A divisão parece ser a ilustre desconhecida o que depois acarreta problemas difíceis de resolver no $4^{\circ}$ e $5^{\circ}$ Anos. Analisando os protocolos de Joana destacamos a importância do diagnóstico em Matemática, para além da produção escritas numéricas, mas também nos cálculos de operações e resolução de situações problema.

Em relação à resolução de situações-problema de composição (campo aditivo), Joana mostra um bom desempenho. Resolve o primeiro problema usando uma técnica operatória. No segundo, usa uma sobrecontagem e desenho para resolver em lugar de realizar uma subtração. 


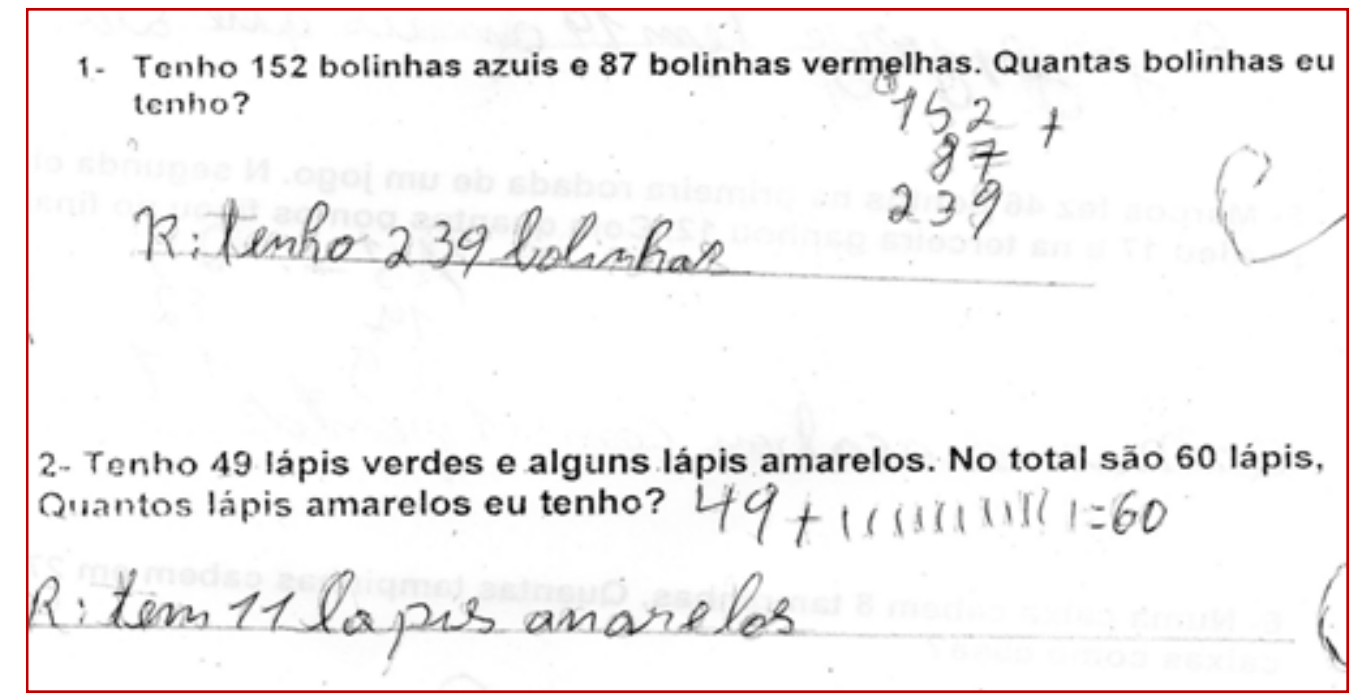

Fonte: Protocolo 18- Joana - Terceiro ano

Nestes outros dois problemas solucionados corretamente, em que o segundo é bastante desafiador, Joana mostra bom domínio dos significados envolvidos.

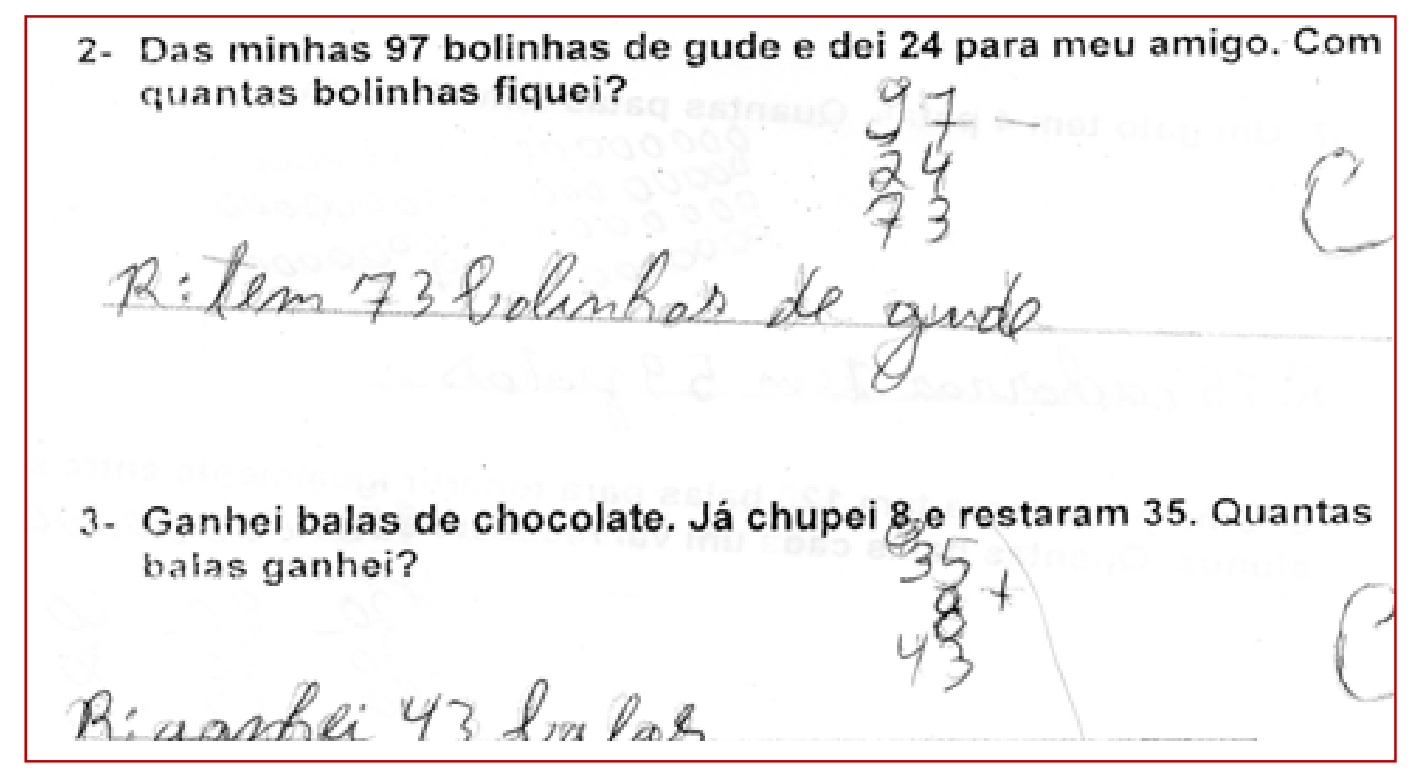

Fonte: Protocolo 19- Joana - Terceiro ano

Novamente Joana recorre à sobrecontagem e desenhos para resolver o problema numa situação de comparação em que a subtração está envolvida. Também acerta o problema de composição de transformações. 


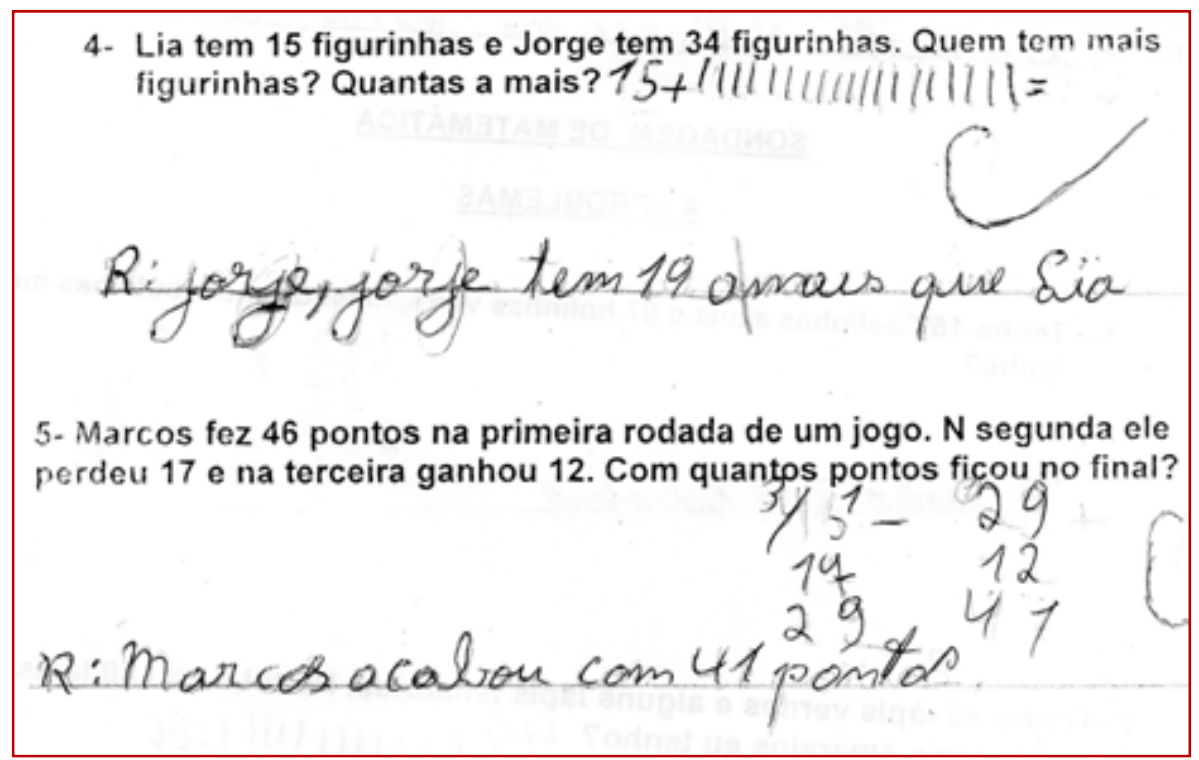

Fonte: Protocolo 20- Joana - Terceiro ano

Embora demonstrando segurança e boa compreensão de situações do campo aditivo, nas situações do campo multiplicativo ela não faz nenhuma tentativa para o problema das tampinhas, que envolve a ideia de proporcionalidade. Resolve o dos gatos por desenho (erra por 1). Na repartição de balas usou subtrações sucessivas, mas não concluiu $30-30=0$, o que levaria à resposta 4.

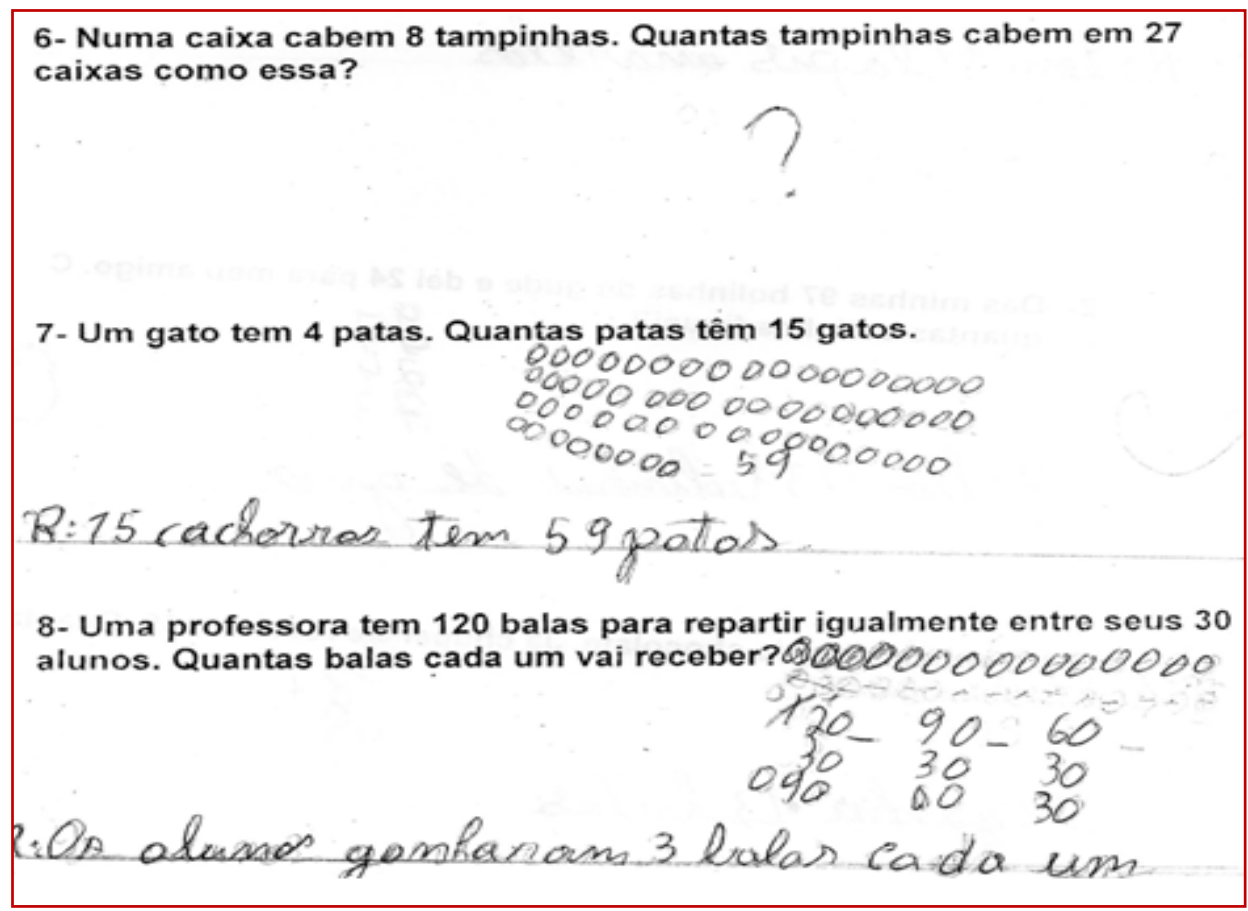

Fonte: Protocolo 21- Joana - Terceiro ano 


\section{Revelações de alunos do quarto ano}

No início do $4^{\circ}$. Ano, Lucas mostra domínio na escrita de números de até 3 ordens, mas não em relação às escritas de números com 4 ordens. Isso é um alerta para nós professores no sentido de que o fato de produzir alguns números não significa estender esse conhecimento automaticamente para qualquer ordem de grandeza. Os números do G4 ditados foram: 3080; 3800. 3008; 4050 e 4500.

\begin{tabular}{|c|c|c|c|c|}
\hline \multicolumn{5}{|c|}{ B-DITADO DE NÚMEROS } \\
\hline G1 & $100^{c}$ & 1080 & 1100 & $1230134^{\circ}$ \\
\hline G2 & $146^{\circ}$ & $164^{0}$ & 1800 & 19902008 \\
\hline G3 & 3580 & $583^{\circ}$ & 8350 & 99901,0000 \\
\hline G4 & 3009 & 3080 & 3008 & 40064050 \\
\hline & 3.080 & 3.800 & & $4.050 \quad 4.500$ \\
\hline
\end{tabular}

Fonte: Protocolo 22 - Lucas - Quarto ano

O desempenho nos cálculos de adição foi bom. Mas a subtração só tem um acerto mostrando falta de compreensão do que está em jogo. No campo multiplicativo novamente seu desempenho é sinal de alerta, em se tratando do inicio do $4^{\circ}$ ano.

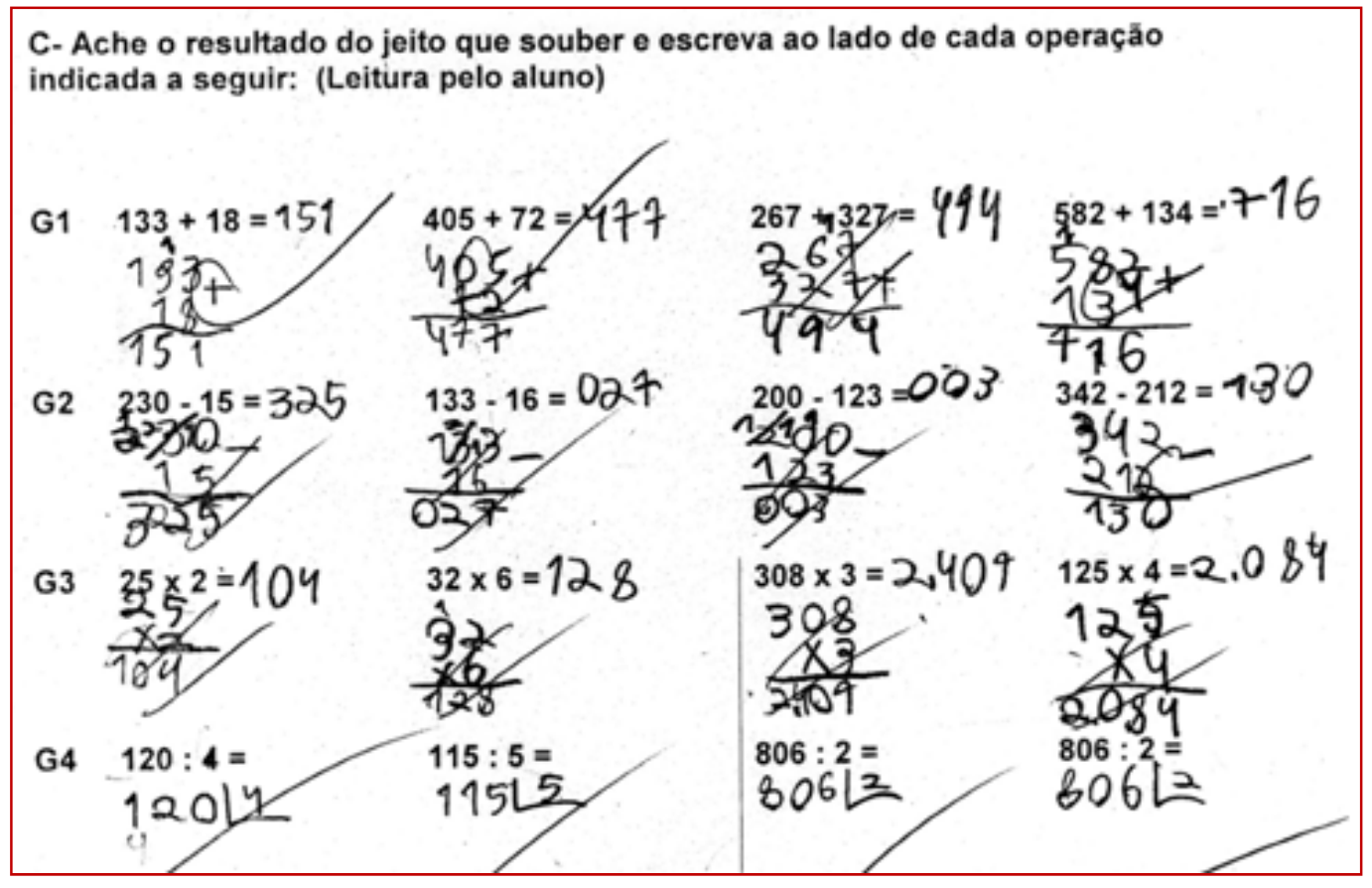

Fonte: Protocolo 23 - Lucas - Quarto ano 
Quanto à resolução de problemas do campo aditivo no $4^{\circ}$ ano observamos alguns protocolos em que não foi conseguido nenhum acerto e outros com excelente desempenho, como o de Henrique em problemas de composição, transformação, comparação e composição de transformações:

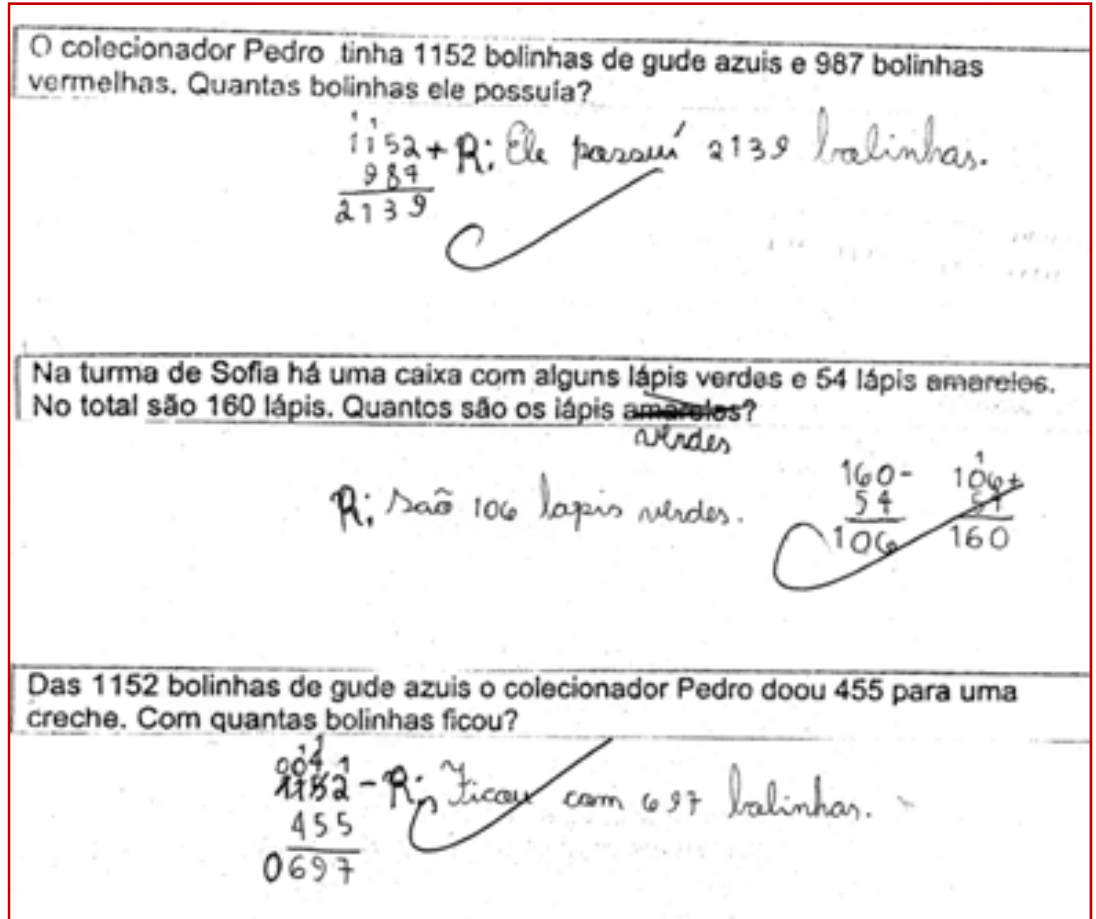

Fonte: Protocolo 24 - Henrique - Quarto ano

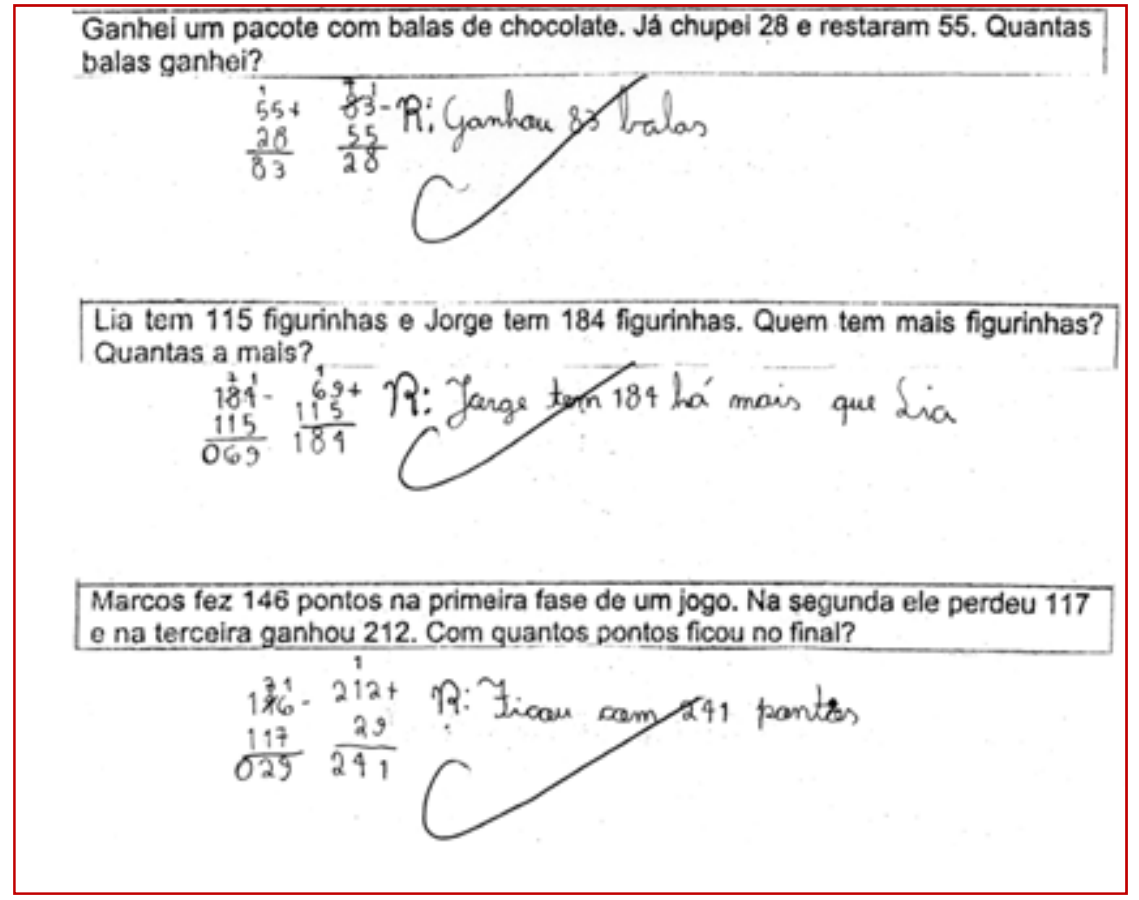

Fonte: Protocolo 25 - Henrique - Quarto ano 
Também na resolução de problemas do campo multiplicativo no $4^{\circ}$ ano foi observada grande discrepância de desempenhos, alguns deixando em branco ou realizado operações que não as adequadas e outros revelando bom desempenho no caso de situações que envolviam multiplicações, como foi o caso de Laura:

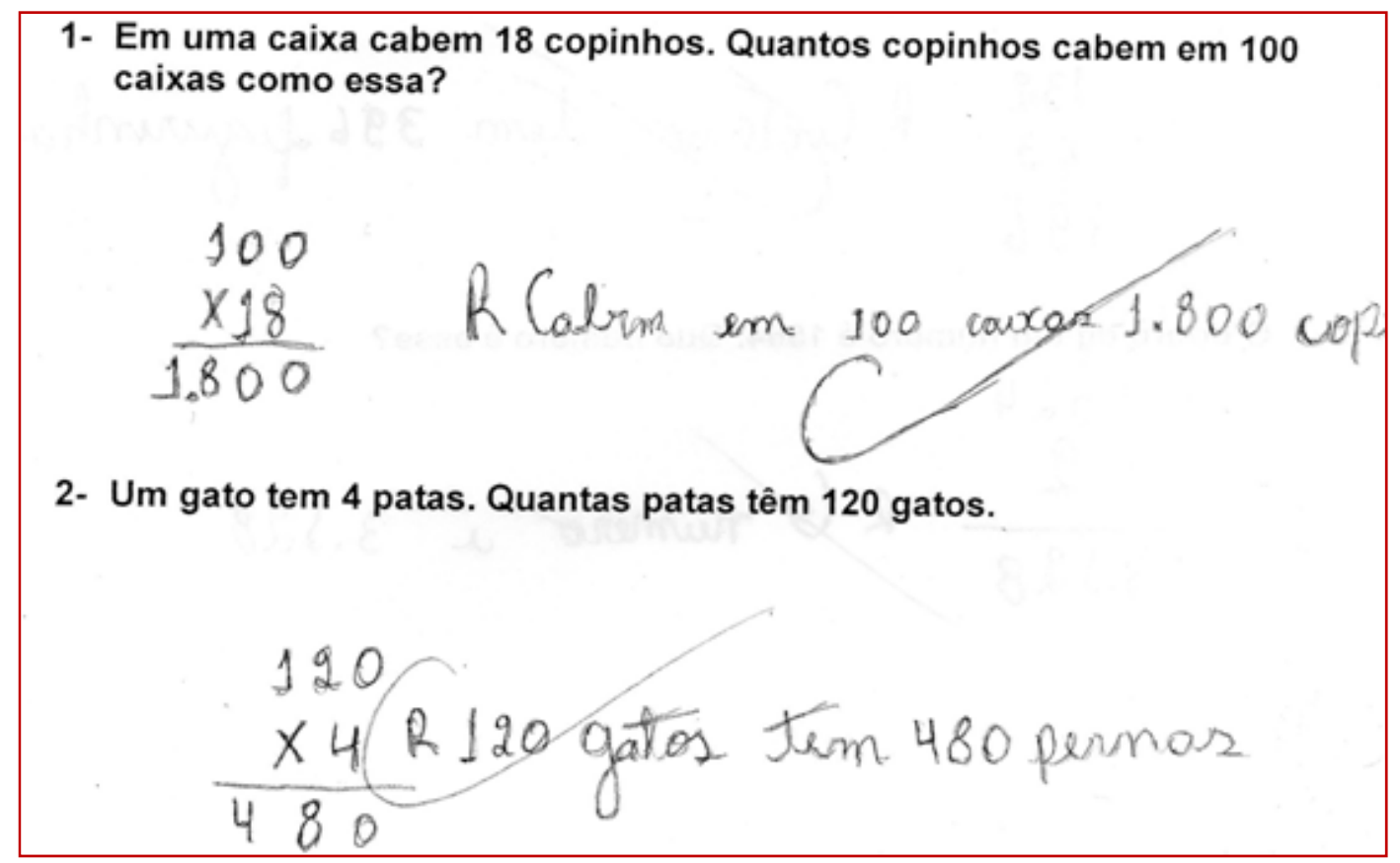

Fonte: Protocolo 26 - Laura - Quarto ano

É interessante observar que essa aluna ainda parece não ter segurança no uso da divisão. No protocolo mostrado a seguir, no problema de repartição de balas ela deve ter feito uma estimativa de que seriam 6 balas e usa a multiplicação para comprovar suas respostas. No problema seguinte (protocolo 28) ela não chega à solução correta e exibe um cálculo que não se sabe o que representa, mostrando a fragilidade do trabalho com a divisão ao longo dos anos iniciais do Ensino Fundamental.

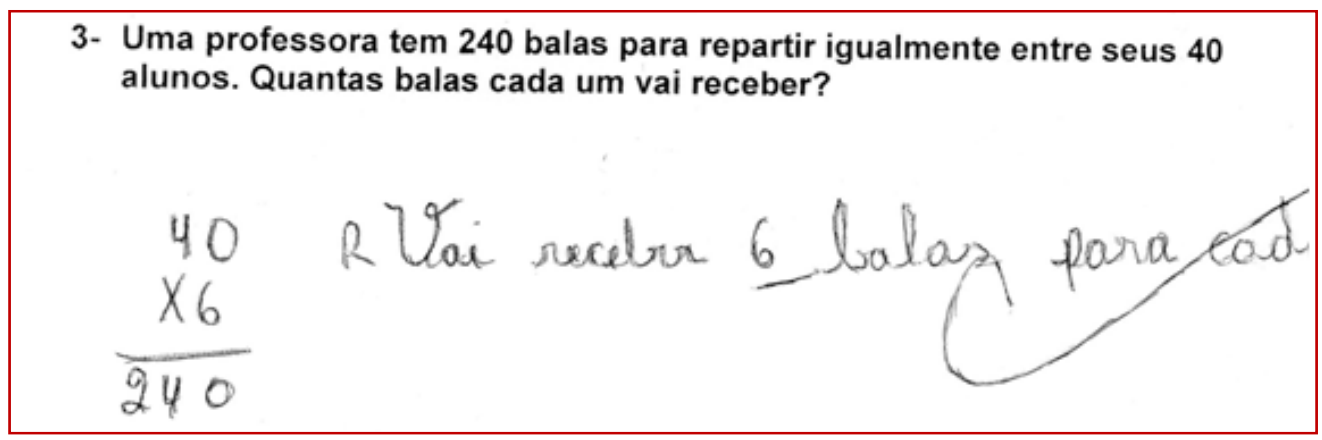

Fonte: Protocolo 27 - Laura - Quarto ano 


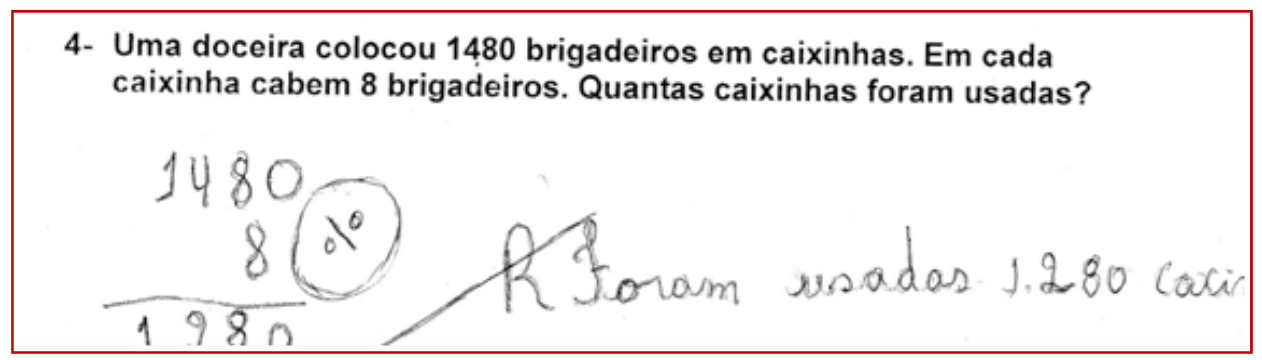

Fonte: Protocolo 28 - Laura - Quarto ano

\section{Revelações de alunos do quinto ano}

No inicio do $5^{\circ}$, ano os alunos de modo geral, demonstraram bom domínio da produção das escritas de números até a ordem das unidades de milhares.

No entanto, ainda no início do $5^{\circ}$ ano alunos como André produzem várias escritas numéricas de forma inadequada, em atividades de ditado de números e também têm baixo desempenho na resolução de problemas.

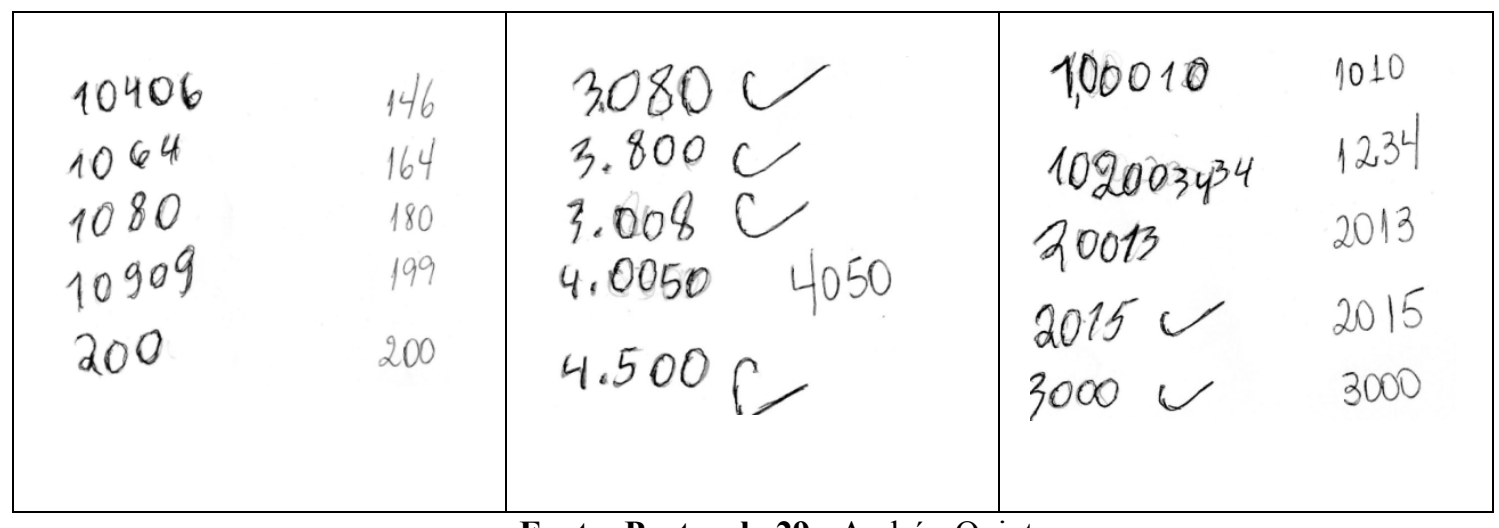

Fonte: Protocolo 29 - André - Quinto ano

Com relação à resolução de problemas do campo aditivo, também foi significativo o número de crianças que identificaram a operação a ser realizada e chegaram aos resultados corretos. É interessante observar na situação-problema 2, que Beth usa ainda a adição para resolver o problema dos lápis. 


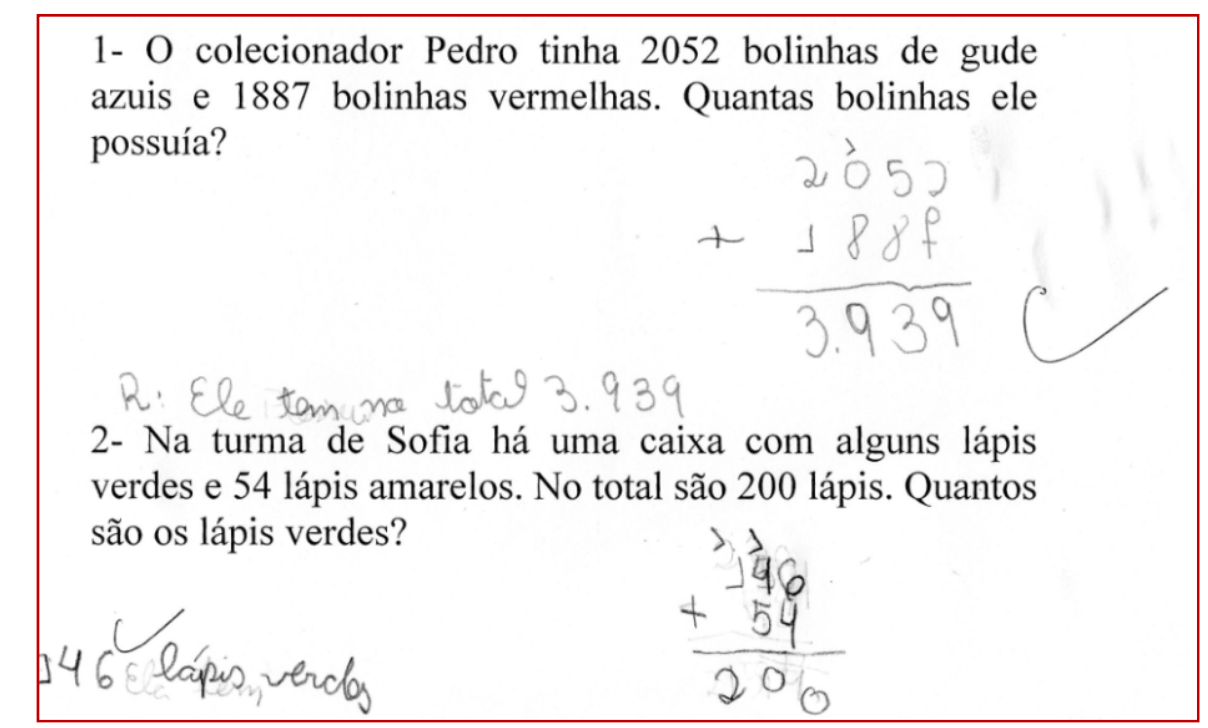

Fonte: Protocolo 30 - Beth - Quinto ano

Mas ainda há dificuldades a serem observadas e trabalhadas. Beth indica a operação correta, mas erra a conta e chega ao resultado 697 mostrando não ter feito nenhuma validação usando a estimativa do valor de 2000 - 500, no problema das bolinhas.

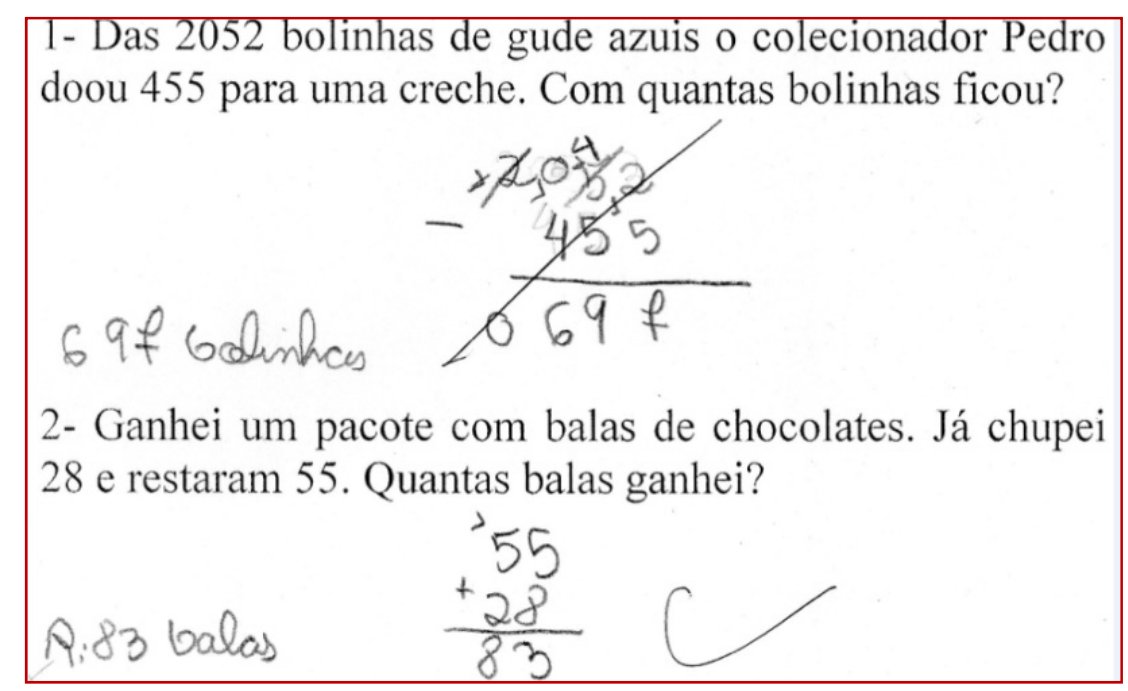

Fonte: Protocolo 31 - Beth - Quinto ano

Beth escolhe adequadamente as operações em problemas de composição, transformação e comparação, mas na situação de composição de transformações não considera os pontos que Marcos perdeu. 


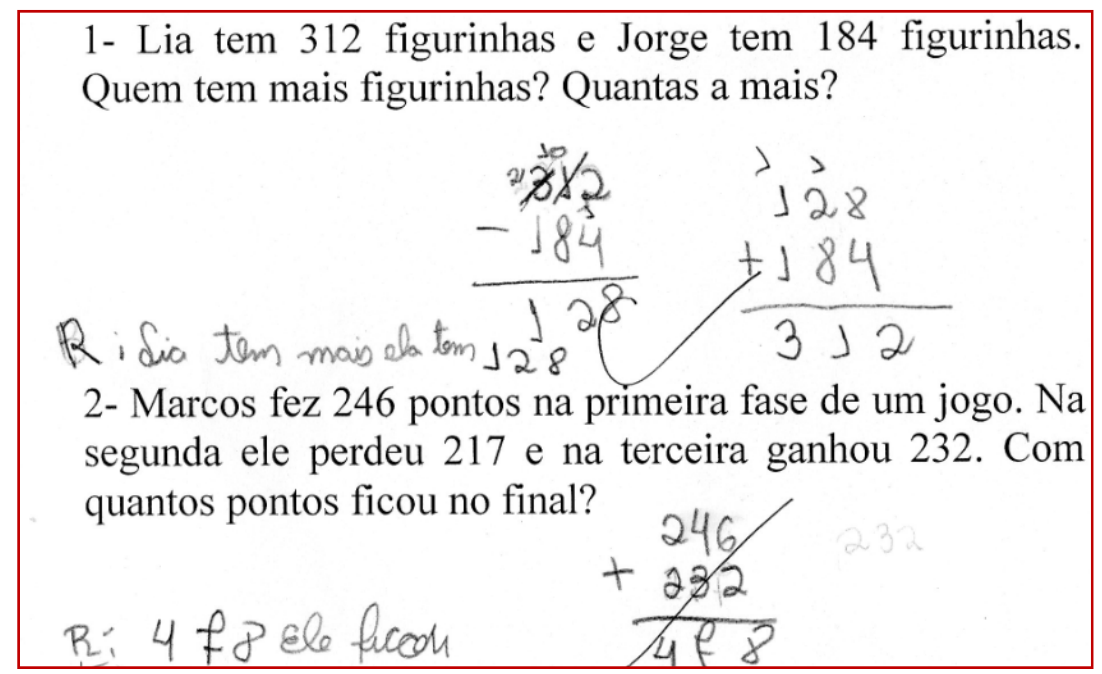

Fonte: Protocolo 32 - Beth - Quinto ano

Beth mostra desempenho ainda bastante insatisfatório na resolução de problemas do campo multiplicativo. No primeiro problema "arma" a conta 160 x 18, mas aparentemente não sabe como resolvê-la, faz corretamente o cálculo 20 x 4; nos dois últimos mostra que a divisão ainda não está compreendida. Ela cancela os dois zeros ficando com a divisão 80:16.

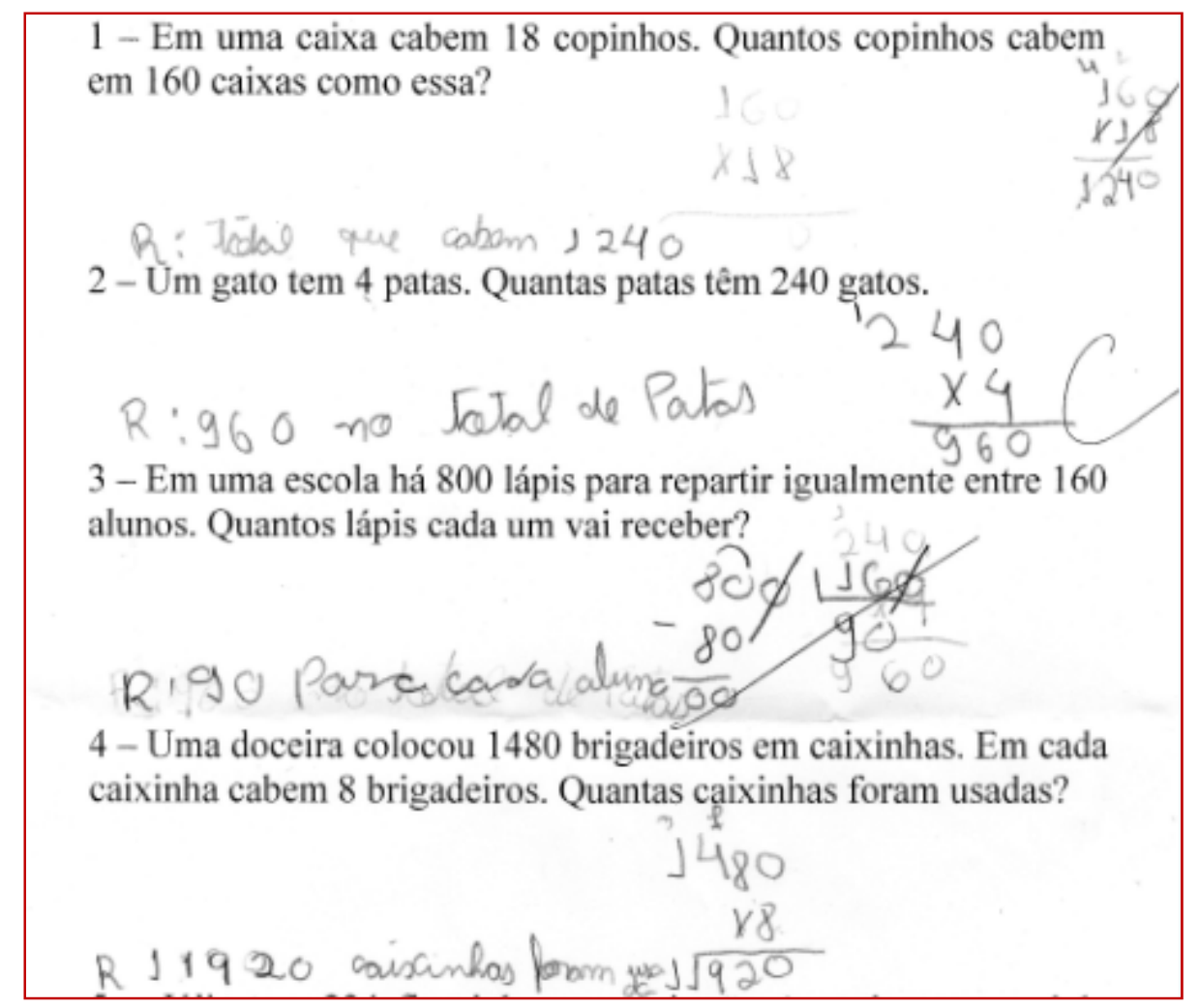

Fonte: Protocolo 33 - Beth - Quinto ano 
Em relação aos cálculos de adição Beth mostra bom desempenho, mas comete erros em subtrações como 200 - 123. As demais calcula corretamente.

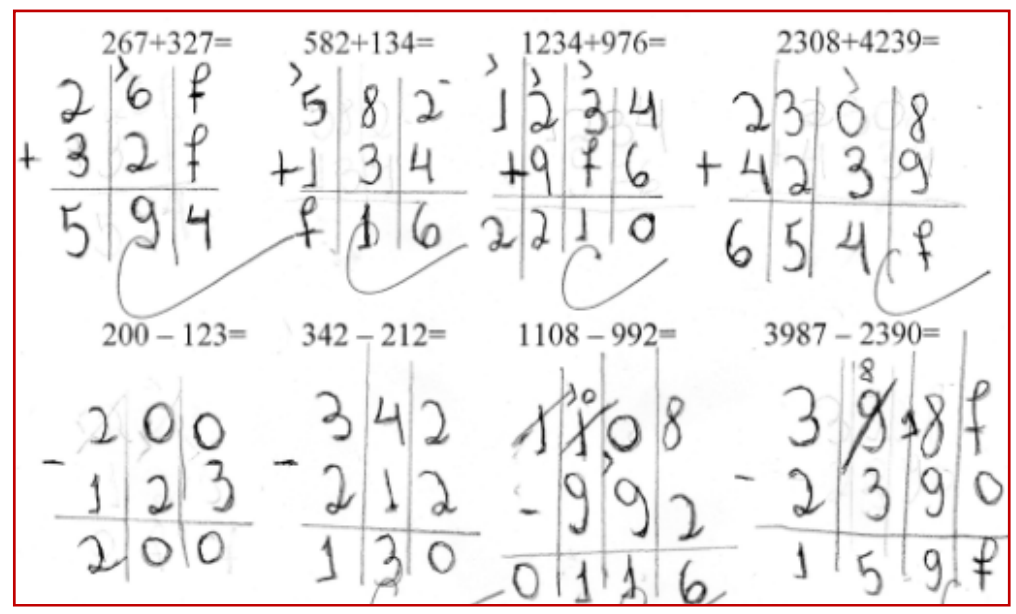

Fonte: Protocolo 34 - - Beth - Quinto ano

No caso dos cálculos de multiplicação e divisão, Beth mostra que provavelmente ainda não aprendeu a multiplicação em que o multiplicador é da ordem das dezenas. A divisão, embora ela saiba armar a conta, ainda tem procedimentos confusos e sem o trabalho essencial com estimativas.

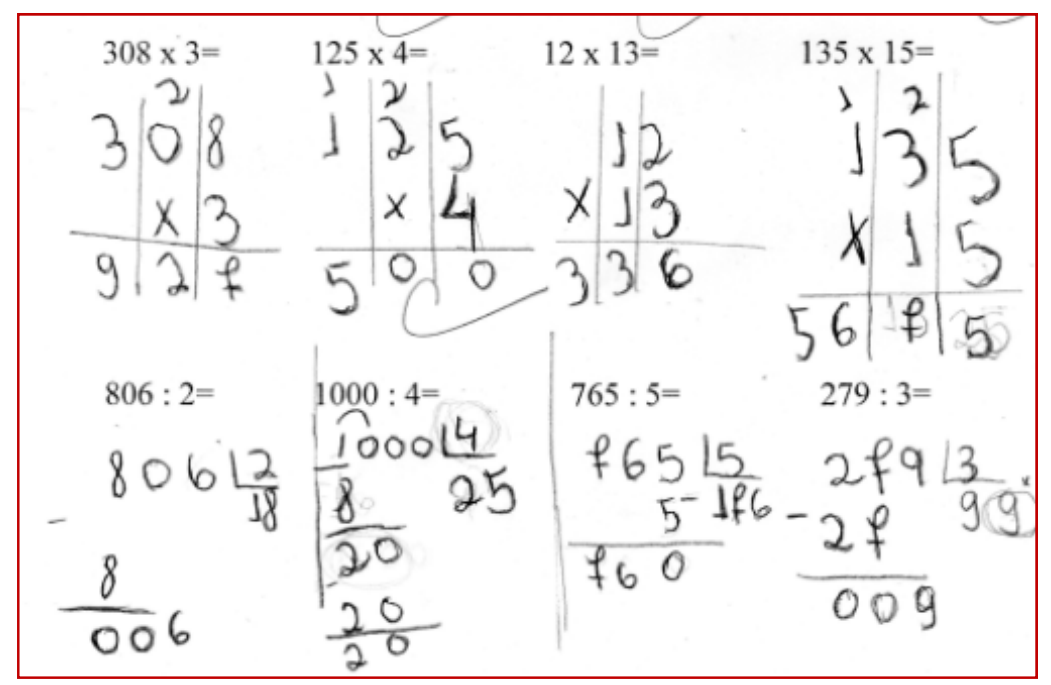

Fonte: Protocolo 35 - Beth - Quinto ano

\section{Considerações finais}

Para finalizar retomamos considerações de Luckesi muito pertinentes e que se mostraram necessárias de retomada no momento atual, particularmente no que se refere aos professores que trabalham nos anos iniciais do ensino fundamental: 


\begin{abstract}
A avaliação é não-pontual, diagnóstica (por isso, dinâmica) e inclusiva. Ou seja, à avaliação interessa o que estava acontecendo antes, o que está acontecendo agora e o que acontecerá depois com o educando, na medida em que a avaliação da aprendizagem está a serviço de um projeto pedagógico construtivo, que olha para o ser humano como um ser em desenvolvimento, em construção permanente. Para um verdadeiro processo de avaliação, não interessa a aprovação ou reprovação de um educando, mas sim sua aprendizagem e, conseqüentemente, o seu crescimento; daí ela ser diagnóstica, permitindo a tomada de decisões para a melhoria; e, consequentemente, ser inclusiva, enquanto não descarta, não exclui, mas sim convida para a melhoria (LUCKESI, 2000, p.4 ).
\end{abstract}

Por reconhecer a importância da avaliação diagnóstica para a tomada de decisão em todo o processo de ensino e de aprendizagem e neste caso especifico no inicio do ano letivo, que, o GRM, no âmbito do Projeto EMAI, situa a discussão sobre avaliação com vistas a trazer contribuições para a melhor compreensão das finalidades da avaliação diagnóstica como instrumento de gestão pedagógica. Assim a análise dos conhecimentos revelados pelas crianças no início do ano letivo, mostra que no campo dos Números Naturais e Operações, um dos principais blocos de conteúdo dessa etapa da escolaridade, vem sendo trabalhado nas escolas.

Acredita-se também que ainda há questões a serem trabalhadas com os docentes, no que se refere à leitura, escrita, comparação e ordenação de números naturais face aos avanços das pesquisas nessa área. Da mesma forma é preciso aprofundar o estudo sobre a importância do trabalho com resolução de problemas explorando seus diferentes significados.

Merece ainda muita atenção o trabalho com o cálculo em suas diferentes modalidades: exato, aproximado, mental, escrito, digital. As técnicas operatórias realizadas sem compreensão pelos alunos ainda persistem embora se observem muitos avanços nos protocolos analisados.

Especial destaque de alerta deve ser feito para as operações no campo multiplicativo e para os cálculos de multiplicação e divisão. Eles precisam ser melhor trabalhados ao longo dos cinco anos iniciais e deverão ainda ser objeto de ensino no $6^{\circ}$. ano do ensino fundamental.

Nas discussões com o GRM ficou evidente que tão importante quanto identificar alguma dificuldade na execução de determinadas tarefas, em relação ao que se espera, é fundamental buscar compreender as possíveis causas de tais dificuldades e suas origens, assim, no início do ano letivo, o professor precisa ter um olhar atento aos alunos que recebe.

Portanto, avaliações servem para diagnosticar os conhecimentos escolares e extraescolares construídos pelos alunos até um dado momento. É com base nesse diagnóstico que o professor pode organizar seu plano de atividades, potencializando os conhecimentos prévios 
dos estudantes. Evidentemente, ao longo do ano, outros diagnósticos precisam ser realizados, para identificar progressos e novas necessidades de intervenção.

A avaliação diagnóstica, em qualquer etapa, visa o aperfeiçoamento do processo de ensino e de aprendizagem, colaborando assim para alunos, professores e equipe pedagógica. Esse movimento pode ter impactos muito positivos na vida escolar, familiar e social de cada um de nossos alunos. Para nós professores, é instrumental decisivo para tomada de decisões. Mas requer uma análise cuidadosa e abertura para entender o que as crianças nos estão "dizendo" para que possamos ajudá-las a avançar.

\section{Referências}

BRASIL. Secretaria Estadual da Educação de São Paulo. Apontamentos sobre concepções que embasam o projeto educação Matemática nos anos iniciais - EMAI. Assessoria e elaboração: Célia Maria Carolino Pires, São Paulo, fev. 2012.

HOFFMANN, Jussara. Avaliação: Mito e desafio - uma perspectiva construtivista. Porto Alegre: Editora Mediação, 1991.

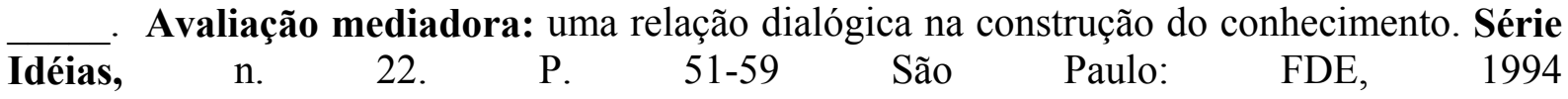
Disponível em www.crmariocovas.sp.gov.br/int_a.php. Acesso em 17/05/2013.

LUCKESI, Cipriano C. Avaliação da Aprendizagem Escolar. São Paulo: Cortez Editora, 2006, $18^{\mathrm{a}}$ edição.

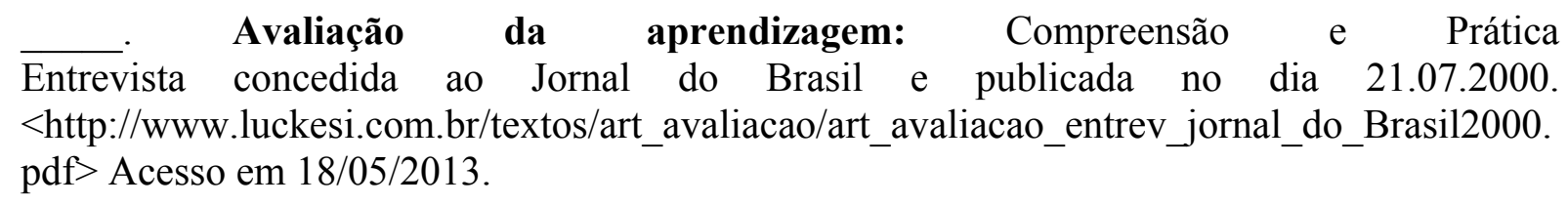
. Avaliação da aprendizagem... mais uma vez. Revista ABC EDUCATIO nº 46, jun.. P.28 e 29.2005

PIRES, C.M.C. Educação Matemática: conversas com professores dos anos iniciais: São Paulo: Zapt Editora Ltda, 2012.

Como eu ensino: Números Naturais e Operações. São Paulo: Melhoramentos, 2013. (no prelo).

SIMON, Martin. Reconstructing mathematics pedagogy from a constructivist perspective. Journal for Research in Mathematics Education, v. 26, nº 2, p.114-145, 1995. 